\title{
UNCERTAINTY MANAGEMENT BY MEANS OF FAIRNESS JUDGMENTS
}

\author{
Kees van den Bos \\ E. Allan Lind
}

\section{Introduction}

The world is an uncertain place. For example, many people have jobs with indefinite tenure, and success at work often depends on adaptability and flexibility in the face of an uncertain future (Lord \& Hartley, 1998). Rapid changes are happening everywhere and news of layoffs and national and international conflicts reaches us almost daily. Above all, people are unpredictable, and most of us have experienced both unanticipated disappointments and unexpected successes in our personal, work, or political worlds. In this chapter, we explore how people use perceptions of fair or unfair treatment to cope with uncertainty in their daily lives. We present a number of studies, most of them very recent, that address the relationship between uncertainty and fairness judgments. We argue that these studies show that when people feel uncertain or when they attend to the uncertain aspects of their worlds they have especially strong concerns about fairness. In addition, we present data showing that sometimes uncertainty can prompt heuristic processing of fairness information. We use these findings to forge a new, more cognitive, theory of fairness judgments and to suggest a new perspective on how people cope with uncertainty.

Fairness plays a key role in people's lives, and a substantial body of research shows that people's beliefs, feelings, attitudes, and behaviors are affected greatly by whether they feel they have been treated fairly or unfairly (for overviews, see, e.g., Brockner \& Wiesenfeld, 1996; Folger \& Cropanzano, 1998; Lind \& Tyler, 1988; Tyler \& Lind, 1992; Tyler \& Smith, 1998). In organizational settings, feeling that one has been treated fairly typically leads to a variety of positive consequences, such as higher commitment to organizations and institutions (Moorman, 1991; 
Folger \& Konovsky, 1989; Korsgaard, Schweiger, \& Sapienza, 1995; McFarlin \& Sweeney, 1992), more extrarole citizenship behavior (Konovsky \& Folger, 1991; Podsakoff \& MacKenzie, 1993), greater likelihood of conflict prevention and resolution (Bobocel, Agar, Meyer, \& Irving, 1998), better job performance (Lind, Kanfer, \& Earley, 1990), and higher levels of job satisfaction (Folger \& Cropanzano, 1998). People who experience unfair treatment, on the other hand, are more likely to leave their jobs (Alexander \& Ruderman, 1987), are less likely to cooperate (Lind, 2001), show lower levels of morale and higher levels of work stress and overt and covert disobedience (Huo, Smith, Tyler, \& Lind, 1996), are more likely to initiate lawsuits (Lind, Greenberg, Scott, \& Welchans, 2000), and may even start behaving in antisocial ways (for reviews, see Greenberg, 1993, 1997; Greenberg \& Lind, 2000).

Outside of organizational contexts the impact of fairness judgments is similarly profound. The belief that one has been treated fairly by judges, the police, or other social authorities enhances acceptance of legal decisions (Lind, Kulik, Ambrose, \& De Vera Park, 1993), obedience to laws (Tyler, 1990), and evaluations of public policies (Lind, 1990; Tyler, Rasinski, \& McGraw, 1985), whereas the belief that one has been treated unfairly has been shown to prompt protest behavior (Vermunt, Wit, Van den Bos, \& Lind, 1996) and recidivism among spousal abuse defendants (Paternoster, Brame, Bachman, \& Sherman, 1997). Because fairness judgments influence so many important attitudes and behaviors, studying why fairness is important to people, how they form judgments of fairness, and what the effects of perceived fairness are on their reactions are crucial issues for understanding how people think, feel, and behave in their social environments (Cropanzano \& Folger, 1989, 1991; Cropanzano \& Greenberg, 1997; Folger \& Konovsky, 1989; Greenberg, 1990, 1993). In this chapter, the psychology of fairness is in fact the primary focus of our attention.

Because norms and values of fairness and justice play such a substantial role in guiding social behavior, it comes as no surprise that fairness judgments have received considerable attention from social psychologists. In fact, the 1976 issue of the Advances in Experimental Social Psychology series focused entirely on the conceptions of fairness and justice that were then current in social psychology (see Berkowitz \& Walster, 1976). Since the mid-1970s the bulk of work on the social psychology of fairness has focused on establishing empirically the consequences of fair or unfair treatment (for reviews see, e.g., Lind \& Tyler, 1988; Tyler \& Lind, 1992). Social psychologists now have lots of evidence of the importance of fairness issues in various real-world settings, and they have identified a variety of ways that fairness affects people's reactions and behaviors. In other words, researchers know quite a lot about what the effects of social fairness are. However, these advances may have been achieved at the expense of deeper insights into what we think are the two most fundamental questions in the psychology of social fairness: why people care about fairness and how fairness judgments are formed. 
We argue in this chapter that relatively little is known about the why and how of perceived faimess and that hard empirical data that can be used to answer these two questions is scarce. We are not alone in this conclusion. Tyler, for example, has proposed that psychologists should explore why fairness matters (Tyler, 1997; Tyler, DeGoey, \& Smith, 1996). Ambrose and Kulik (2001) recently have argued that little is known about the processes by which fairness judgments are formed. In this chapter we present an overview of the empirical work (largely theory-driven laboratory experiments) that we and other researchers have conducted since the early 1990s on issues surrounding the how and why of fairness judgments. We then draw on this work as we put forward a new theory of the social psychology of fairness judgments.

The new studies we review and the theory we propose are unusual for the social psychology of fairness because they analyze fairness judgments from a frankly cognitive perspective. There has been a strong tendency in fairness studies conducted since the mid-1970s to analyze the psychology of fairness as a component of the social psychology of groups, without much concern for the cognitive dynamics involved. For example, three well-known theoretical accounts of procedural fairness - the Thibaut and Walker (1975) instrumental model, the Lind and Tyler (1988) group-value model, and the Tyler and Lind (1992) relational model-have all emphasized group-oriented aspects of fairness effects. Although these prior models have been important for the development of the social psychology of fairness, they have largely neglected the cognitive basis of fairness. In this chapter we begin to fill this gap. This is not to say that all previous theories totally neglected the cognitive foundations of justice (see, e.g., Folger, 1986; Messick, 1993), but our model is new, we think, in its explicit emphasis on the social-cognitive aspects of the psychology of fairness judgments. Thus, we make the case for a perspective on fairness that incorporates both the social and cognitive aspects of fairness.

In the empirical work we describe later we used cognitive-oriented analyses to make and test predictions concerning the why and how of fairness judgments. What we try to do in the current chapter is to integrate these various empirical articles, draw new conceptual conclusions, present a social-cognitive model of the psychology of fairness, and discuss the implications of this model. We argue that fairness matters so much to people because fairness helps them to deal with uncertainty. As social or cognitive conditions arise that prompt concerns about uncertainty, we suggest, people become especially attentive to the information they need to form fairness judgments because solid, firmly constructed fairness judgments either remove uncertainty or alleviate much of the discomfort that uncertainty would otherwise generate.

The remainder of this chapter consists of six sections. In the next two sections we discuss our conceptualization of uncertainty and fairness. After this, we lay out in three sections the empirical basis for our social-cognitive model. We do this by reviewing a number of recent studies which, we argue, demonstrate that 
people show a special need for firm fairness judgments in uncertain situations. Following this, we suggest that both the why and how of social fairness are affected considerably by uncertainty: Fairness matters to people because it is important in processes of uncertainty management and because uncertainty has a crucial role in the construction of fairness judgments. We close by discussing some implications of our theory and drawing conclusions.

\section{Uncertainty in Social Life}

Because we propose that uncertainty plays a crucial role in the psychology of fairness judgments, it is important to describe how we use the term "uncertainty" in this chapter and how this definition is related to concepts like confidence, control, and self-esteem. This is what we do in the current section.

Psychologists tend to think of uncertainty as meaning either the belief that something is probabilistically determined or the belief that however deterministic an event is, one does not understand the event well enough to predict it. In the literatures on behavioral decision making and game theory the word is used to refer to the belief that one has only probabilities of events to work with in making a decision. Thus, a classic gamble is a decision under uncertainty (Kahneman, Slovic, \& Tversky, 1982; Tversky \& Kahneman, 1974). Social psychologists often extend that to mean that one's own level of understanding is such that one cannot say for sure what will happen, even in situations where more information might be available outside the person (e.g., De Vries \& Wilke, 1991; Sniezek, May, \& Sawyer, 1990; Van Dijk, Wilke, Wilke, \& Metman, 1997). So people might say they are uncertain about whether someone can be trusted because they do not know that person well enough to make a certain judgment about trustworthiness (Van den Bos, Wilke, \& Lind, 1998). Generalizing the same concept still further, social psychologists often talk about uncertain situations; situations in which one feels that one does not really understand important features of the situation or that one does not have sufficient information about relationships, agendas, or norms (cf. Garner, 1962; Kagan, 1972).

It is this last, broad sort of uncertainty that we are addressing in this chapter. More specifically, following Kagan (1972) and Sorrentino and his associates (Sorrentino, Hodson, \& Huber, in press; Sorrentino, Short, \& Raynor, 1984), our theory about uncertainty management considers management of uncertainty a rather basic motive and argues that uncertainty occurs either when a person confronts an inability to predict the future or when a person confronts an incompatibility between different cognitions, between cognitions and experiences, or between cognitions and behavior. Thus, situations, social or not, that provoke feelings of uncertainty, doubt, or confusion will, we argue, meet our definition of uncertainty 
and provide the stimulus for seeking and using fairness judgments. The key element is the salience of either the unpredictability of future events or the inconsistency between important cognitions, experiences, or behaviors. As is shown later when we present research relevant to our theory, the range of uncertainty-provoking situations is quite broad (see also McGregor, Zanna, Holmes, \& Spencer, 2001): In the empirical work we describe later, uncertainty is induced by a variety of situations ranging from forced contemplation of death to interaction with a new supervisor in an experimental work group.

This broad conception of uncertainty allows us to draw on various research traditions, such as theories of uncertainty resolution (see especially Section IV), human judgment under uncertainty (see especially Section V), and anchoring effects in uncertain situations (see especially Section VI), that are useful for our study of the psychology of fairness judgments. This conception encompasses both cognitive and affective aspects of uncertainty, temporary and stable aspects of uncertainty (we call this state and trait uncertainty, respectively), and social contextual factors and individual differences in uncertainty orientation (Sorrentino et al., 1984). After all, uncertainty can be produced by contextual factors that challenge people's certainty about their cognitions, perceptions, feelings, and behaviors and ultimately their certainty about and confidence in their sense of self (Hogg, in press). This self-certainty can be very important because the self-concept is the critical organizing principle, referent point, or integrative framework for diverse perceptions, feelings, and behaviors. The locus of uncertainty can be found in many aspects of the social context, and therefore anyone is prone to uncertainty. However, biographical factors also affect stable individual differences in levels of uncertainty and impact people's orientation toward how they manage uncertainty (Sorrentino et al., 1984, in press). Furthermore, people strive more strongly, of course, for certainty about aspects of life which are important to them (Hogg \& Mullin, 1999).

We argue here that people have a fundamental need to feel certain about their world and their place within it and that too much uncertainty threatens the meaning of existence. Uncertainty can be threatening, and people generally feel a need either to eliminate uncertainty or to find some way to make it tolerable and cognitively manageable. As we note below, it remains to be seen whether fairness has its ameliorative effect on uncertainty by making things seem more certain, by making uncertainty more tolerable, or both. Consider the threats that can accompany uncertainty: Uncertainty deprives one of confidence in how to behave and what to expect from the physical and social environment within which one finds oneself. Uncertainty about one's attitudes, beliefs, feelings, and perceptions, and about one's relationship to other people, is generally aversive (e.g., Fiske \& Taylor, 1991; Hogg, in press; Lopes, 1987; Sorrentino \& Roney, 1986) because it is ultimately associated with reduced control over one's life. Thus, uncertainty often motivates behavior that reduces subjective uncertainty. For example, 
McGregor et al. (2001) found that after induced personal uncertainty, individuals became more rigid and close-minded about their attitudes, values, and identifications and planned to engage in more self-consistent activities. Doing so effectively eliminated the psychological discomfort associated with uncertainty. Epistemic motives related to uncertainty are important social psychological phenomena. Festinger (1954), for example, based social comparison theory on the proposition that knowing that one is correct is a critical human motivation that drives people to make interpersonal social comparisons when nonsocial means are unavailable.

Thus, we argue that uncertainty plays an important role in human life. This is not to say that people want to reduce uncertainty all the time. Of course, being completely certain about all or many aspects of one's life may make one's life rather dull and there are clearly instances in which people strive for uncertainty rather than seek to reduce it. Sometimes people want to experience new, uncertain events, and on occasion they even seek the thrill of possible danger, like bungee jumping or parachuting. Furthermore, the uncertainty involved in a fair gamble is stimulating, at least for some people. But even when uncertainty is sought, it usually is still managed (at least to some extent). Related to this, a growing literature on organizational risk taking has as its basis the proposition that innovation, entrepreneurship, and ultimately business success in a changing environment depends not on avoiding uncertainty but instead on managing it (see generally MacCrimmon \& Wehrung, 1986; Shapira, 1995). But whether uncertainty is avoided or managed, it is clear that uncertainty and how people manage it are important issues in human life. We propose here that there are good reasons to assume that uncertainty and uncertainty management play a crucial role in the psychology of fairness judgments.

Confidence is a concept that is closely related to certainty, as we use the term here (Kuhn \& Sniezek, 1996). Confidence tends to refer to feelings of certainty, with more of a cognitive and sometimes even an affective component. Lack of confidence implies more fear of error than does raw uncertainty. People would only say that someone lacked confidence about something that should be known or understood (cf. Treadwell \& Nelson, 1997). People might feel uncertain about a gamble, but they would not often say they lacked confidence about it because the inherent probabilistic nature of a gamble means that no one could be confident. Feelings of confidence in social situations touches on the issue of self-esteem (cf. Leary \& Baumeister, 2000) because the confidence that one can handle social situations is a component of self-confidence (cf. Hogg \& Mullin, 1999).

Control is a feeling that one can affect things in predictable ways (e.g., Langer, 1975; Thibaut \& Walker, 1975; Thompson, Armstrong, \& Thomas, 1998; for an exception, see Nickels, Cramer, \& Gural, 1992), so this concept too is related to certainty and uncertainty. As we social psychologists use the term, control implies that one can (or has the illusion that one can) change one's own outcomes or 
one's situations if one wishes to do so (Tan \& Lipe, 1997). Confidence and control are related in that both seem to be reassuring and to promote feelings of being an effective actor in one's social context (Spreitzer \& Mishra, 1999), but logically people could be confident about things they have no control over (cf. Langer, 1975). Another link is that when individuals talk about self-confidence the implication is that self-confident people either have control over events in their lives or have the belief that they can deal with events that they cannot control (cf. Loewenstein, 1996; Ric, 1997).

This brings us ultimately to the concept of self-esteem. Most American and European psychologists, it seems to us, assume that confidence and feelings of control are components of positive self-esteem and that the absence of these lead to low self-esteem (cf. Brockner et al., 1998; Greenberg, Solomon, \& Pyszczynski, 1997; Heatherton \& Polivy, 1991; Hogg \& Abrams, 1990; Koper, Van Knippenberg, Bouhuijs, Vermunt, \& Wilke, 1993; Leary \& Baumeister, 2000; Rosenberg, 1979; Smith \& Tyler, 1997). Some Eastern philosophies and cultures might question this (see, e.g., Martin, 1999), but the Western psyche, it seems to us, does not have much appreciation of the possibility that one can have a more passive, less controlling view of the universe and still be content with oneself. More important for the current purpose is that Western people (including Western social psychologists) might well say that people with low self-esteem are uncertain about themselves (cf. Hogg, in press). People can be certain that everything they do is bad and hence have low self-esteem, but it is more common for people who are certain about themselves to have high self-esteem. This suggests that self-esteem, like confidence and control, to some extent is different from certainty and to some extent shares similar elements with it. In the present chapter, we are interested more in the similarities these concepts share, but mention important distinctions where necessary.

Now that we have discussed how we treat uncertainty and related concepts here, we discuss in the next section how we define the concept of fairness judgments. After this, we discuss empirical studies that show that uncertainty is important in the why and how of the psychology of fairness judgments.

\section{Fairness Judgments}

Fairness, as we psychologists study it, is an idea that exists within the minds of individuals (Adams, 1965; Lind \& Tyler, 1988; Tyler, Boeckmann, Smith, \& Huo, 1997). This subjective sense of what is fair or unfair is the focus of the psychology of fairness and can be contrasted with objective principles of fairness and justice that are studied by philosophers, among others (for an overview, see Cohen, 1986). 
Unlike the objective principles of fairness and justice, subjective feelings about fairness and unfairness are not necessarily justified by reference to the external standards of what is fair and just proposed by philosophical (and other normative) theories of justice. Rather the concern of psychologists is what people think is fair and unfair.

Thus, we agree with Mikula and Wenzel (2000) that the emphasis of psychologists on fairness judgments is important because abstract philosophical principles of justice allow for a diversity of different translations into concrete terms. To be sure, judgments of fairness and justice may be socially shared, but such a consensus indicates only grounds for intersubjectivity, not for objectivity. Thus, as we approach them, fairness judgments are always subjective judgments and the aim of our psychological study of social justice is to understand the causes and consequences of subjective fairness judgments (cf. Mikula \& Wenzel, 2000; Tyler et al., 1997).

It is important to emphasize here that judgments of what people judge to be fair and judgments of what they consider to be just or morally right might differ substantially. "Justice" and "morality" are often seen as more formal terms, and they carry a connotation of legal authority and ethical rules that is precisely what we do $n o t$ mean in most psychological theorizing and research on the topic. In contrast "fairness" better connotes the subjective, ready judgment that is and has long been the true topic of psychological study. We have the impression that participants in research studies find it easier and more relevant to provide judgments of fairness than judgments of justice or morality. This is the reason, we assume, that most social psychologists in our field usually ask people to rate fairness rather than to rate justice or morality (see, e.g., the list of measures in the Appendix of Tyler \& Lind, 1992), and this is the reason that we prefer to use the label "fairness judgments" rather than "justice judgments" or "judgments of morality." "Fairness judgments" simply reflects better both common research practices and the core belief under study. ${ }^{1}$ Thus, notwithstanding the fact that social psychologists usually call this area "the psychology of social justice," we speak here of the "psychology of fairness judgments," and we talk about fairness judgments as both our major theoretical construct and as what is being measured in our studies, noting when other measures are used.

\footnotetext{
"It is true that the terms "fairness" and "justice" can be distinguished in English (as can the Dutch equivalents eerlijkheid and rechtvaardigheid). However, the distinction may be more difficult to make in other languages. In French, for example, relevant nouns include justesse versus justice, and the distinction between the two does not correspond very well to the fairness-justice distinction in English and Dutch. This does not invalidate the point we are making here; it only suggests that it is perhaps easier to talk about distinctions between faimess and justice in English and Dutch than in some other languages. Another advantage to shifting our terminology to fairness is that, in English and Dutch at least, the term "social justice" tends to suggest a philosophy of income and power redistribution in society, and this is not in fact what we usually study.
} 


\section{Uncertainty and the Why of Fairness Judgments: Uncertainty Enhances Concerns for Fairness}

It is time now to discuss the research evidence on the role of uncertainty in the psychology of fairness. In the current section we describe research findings that show that uncertainty is a key factor in why people care about fairness. More specifically, we review studies that show that fairness matters more to people (a) when they are uncertain about a social authority's trustworthiness, (b) when they are uncertain about their life situation as a consequence of being reminded of their mortality, and (c) when they are prompted to attend to uncertain aspects of their lives. After we have given an overview of these studies, we discuss other research findings that converge on the same point-that people have a greater interest in, and arguably a greater need for, fairness in uncertain as opposed to certain situations. Studies that are important for our line of reasoning are discussed more extensively, but, for details of a particular study, the reader is referred to the write-up of that study.

\section{A. UNCERTAINTY ABOUT AN AUTHORITY'S TRUSTWORTHINESS}

In our 1998 article with Henk Wilke, we set out to provide an answer to the question of why fairness matters to people (Van den Bos, Wilke, \& Lind, 1998). We took as a starting point the idea in fairness heuristic theory (e.g., Lind, 1992, 2001; Lind et al., 1993; Van den Bos, Lind, \& Wilke, 2001) that people especially need fairness judgments when they are concerned about potential problems associated with social interdependence and socially based identity processes. The tension between the benefits of interdependence and social identity on the one hand and the risks associated with interdependence and social identity on the other has been termed "the fundamental social dilemma" (e.g., Lind, 1995). In essence, this dilemma is concerned with the question of whether one can trust others not to exploit or exclude one from important relationships and groups (cf. Huo et al., 1996; Lind \& Tyler, 1988; Smith, Tyler, Huo, Ortiz, \& Lind, 1998; Tyler \& Lind, 1992).

An important subgroup of social relations are authority processes. Based on the work by Tyler and Lind (1992; Lind et al., 1993; Tyler \& DeGoey, 1996), we argued that because ceding authority to another person raises the possibility of exploitation and exclusion, people frequently feel uneasy about their relationship with authorities and about the outcomes they receive from the authority. We reasoned that when people are trying to decide how to react to an outcome they received from an authority, they want to have information about whether they can trust the authority. 
Furthermore, we posed the question: Do people often have direct information about an authority's trustworthiness? We suggested that, in many social, organizational, or political contexts, they do not (cf. Winder, Kerkhof, \& Klandermans, 1999). Continuing our reasoning along the lines suggested by fairness heuristic theory, we reasoned that even, and perhaps especially, if people do not have information about the authority's trustworthiness, they must find some way to judge the outcome they received from the authority. How do they do this? We suggested that in such situations-in which people are, in essence, uncertain about authority's trustworthiness - decisions about how to react to outcomes are made through reference to judgments about the fairness of the authority's procedures. In other words, in situations in which definitive trust information is lacking, procedural fairness serves as a heuristic substitute in the process of deciding how to judge an outcome one has received from the authority. As a consequence, we expected that when people have no information about authority's trustworthiness, they will react more positively toward the outcome they received from the authority when they believe that the authority had been employing fair as opposed to unfair procedures.

On the other hand, this line of thought also suggests that when people do have direct, explicit information about authority's trustworthiness-when they are, in terms of our current analysis, more certain about the nature of the authoritythey are less in need of procedural fairness as a heuristic substitute. We therefore expected that when people do not have information about an authority's trustworthiness, they would show what is usually termed a fair process effect (Folger, Rosenfield, Grove, \& Corkran, 1979). That is, they would react more positively toward the outcome they received from the authority when the authority had been employing a fair as opposed to an unfair procedure. In contrast, according to this reasoning, less strong fair process effects should occur when people have direct information about authority's trustworthiness.

We conducted two experiments to test these predictions. The first experiment was a scenario experiment and the second study was an experiment in which participants actually experienced manipulations of authority's trustworthiness and procedure. Both experiments showed evidence that supported our line of reasoning. We describe here only the second, experiential experiment. In that study, participants were placed in separate cubicles, each of which contained a computer with a monitor and a keyboard. Participants were told that the computers were connected to one another and that people in the cubicles could communicate with each other by means of the computer network. The computers were used to present the stimulus information and to collect data on the dependent variables and the manipulation checks. Participants were informed that they participated in the study with two other persons. One of the three participants would be appointed to the position of supervisor, referred to as position A. The other two 
persons would be assigned to the positions of work performers, labeled as positions B and C. After this, positions were assigned. Participants were, in fact, always appointed to position B. Participants were informed that the person appointed to $\mathrm{A}$, the supervisor position, was given that appointment because of his or her experience in another, comparable study and that those appointed to positions $\mathrm{B}$ and $\mathrm{C}$ were assigned to these positions because they did not have this experience.

The experimental procedure was then outlined to the participants: After the experimental tasks were explained, participants would practice the tasks for $2 \mathrm{~min}$, after which time they would work on the tasks for $10 \mathrm{~min}$. Furthermore, it was communicated to the participants that, after all sessions of the experiment were completed, a lottery would be held among all participants. The winner of this lottery would receive 100 Dutch guilders. (Actually, when the experiment was complete, the 100 Dutch guilders were randomly given to one participant; a procedure to which none of the participants objected upon debriefing.) Participants were informed that a total of 200 lottery tickets would be divided among all participants. Participants were further told that after the work round the person appointed to position A would divide some lottery tickets between the participant and the person supposedly in position $\mathrm{C}$.

After the task that participants would perform had been explained, the trust information that participants received was manipulated. In the trust-certain-positive and trust-certain-negative conditions, participants were presented with fictitious survey results allegedly filled in by persons who had participated with $\mathrm{A}$ in a prior study: In the trust-certain-positive condition, participants were informed that A had been rated as very trustworthy. A had received a mean score of 6.9 on a 7 -point scale ranging from not to be trusted at all (1) to to be trusted completely (7). The majority of the scores had been 7 , and the lowest score that had been given to $\mathrm{A}$ was 6 . In the trust-certain-negative condition, participants were informed that A had been rated as very untrustworthy. A had received a mean score of 1.1 on the 7 -point scale. The majority of the scores had been 1 , and the highest score given to $\mathrm{A}$ was 2 . In the trust-uncertain condition, participants received no information about A's trustworthiness.

After this, participants worked on the tasks for $10 \mathrm{~min}$. Participants were then told how many tasks they had completed in the work round, and-to ensure that participants compared themselves to $\mathrm{C}$ and to make this study comparable with our other experiments (Van den Bos, 1999; Van den Bos, Lind, Vermunt, \& Wilke, 1997; Van den Bos, Wilke, Lind, \& Vermunt, 1998) - the participants were told that $\mathrm{C}$ had completed an equivalent number of tasks. Participants were then told that $\mathrm{A}$ would divide the lottery tickets between them and $\mathrm{C}$. All participants were asked to think for $1 \mathrm{~min}$ about the percentage of lottery tickets that they should receive relative to $\mathrm{C}$ and to write down this percentage on the piece of paper next 
to the computer. ${ }^{2}$ Participants were informed that at the end of the experiment the pieces of paper would be thrown way.

We manipulated the procedure that the participants encountered next (cf. Van den Bos, 1999; Van den Bos, Lind, et al., 1997; Van den Bos, Wilke, Lind, \& Vermunt, 1998). In the voice condition, A (the supervisor) allegedly asked the participants, by means of the computer network, to type in their opinion about the percentage of tickets that they should receive relative to C. Participants in the novoice condition were informed that they would not be asked to type their opinion about the percentage of tickets that they should receive relative to $\mathrm{C}^{3}$

Participants then received three lottery tickets (and were not informed about the number of tickets $C$ received). Dependent variables and manipulation checks were then assessed. The dependent variable that we discuss here asked participants to rate how satisfied they were with the three lottery tickets that they received. When the participants had answered the dependent variables and manipulation checks, they were thoroughly debriefed and paid for their participation.

As predicted, participants' outcome satisfaction judgments showed a strong interaction effect. Figure 1 shows the effect. A strong, significant procedure effect was found in the condition where participants were uncertain about whether they could trust the authority: In this condition participants were more satisfied with their outcome when they had received an opportunity to voice their opinions than when they not had received such an opportunity. Weaker, nonsignificant, procedure effects were seen when participants knew that they could or could not trust the authority, indicating that in these conditions outcome satisfaction did not differ as a function of voice versus no-voice procedures.

Thus, these results show that people's reactions to an outcome they received from an authority are strongly affected by procedural fairness information when they do not know whether the authority can be trusted. When people subject to authority are uncertain about the authority's trustworthiness they are more willing to accept the outcomes the authority gives to them if those outcomes are allocated

\footnotetext{
${ }^{2}$ The percentages of lottery tickets that participants believed that they should get relative to the other participant and which they wrote down on the pieces of paper showed no significant effects of manipulations. As in the other experiments to be presented here, the great majority of the participants indicated that they should get $50 \%$ of the tickets (in this experiment, 130 of 138 participants did so: the grand mean percentage was $50.3 \%$ ). Similarly, and in correspondence with the other experiments to be discussed in this chapter, the great majority of the participants who were allowed voice typed in that they should receive $50 \%$ of tickets (in the current experiment 68 of 69 participants did so, and the mean percentage was $50.7 \%$ ). These findings are congruent with equity theory: Participants preferred to divide outcomes equally between themselves and the other participant (who contributed an equal amount of inputs and who hence deserved-according to equity theory-to receive the same amount of outputs as the participants themselves).

${ }^{3}$ As in most experiments discussed in this chapter, research findings showed that participants judged their procedure to be more fair following an opportunity to voice their opinions than following no such opportunity. This suggests that the manipulation of procedural fairness was perceived as intended.
} 


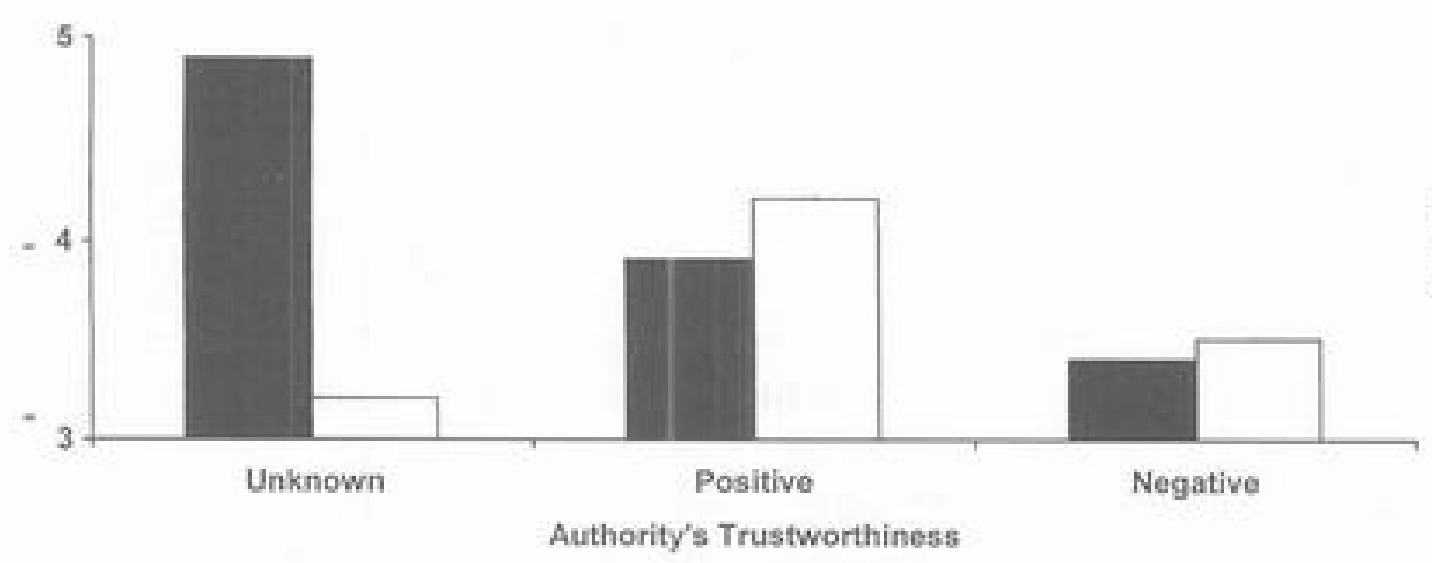

Fig. 1. Mean outcome satisfaction judgments as a function of authority's trustworthiness and procedure (Van den Bos, Wilke, \& Lind 1998, Experiment 2). Means are on 7-point scales with higher values indicating more positive ratings of outcome satisfaction. (Van den Bos, K., Wilke, H. A. M., \& Lind, E. A. (1998). When do we need procedural fairness?: The role of trust in authority. Journal of Personality and Social Psychology, 75, 1449-1458. Copyright 01998 by the American Psychological Association. Adapted with permission).

by fair rather than unfair procedures. However, when people have been informed about the authority's trustworthiness - when their certainty about the authority is strong - they make less use of procedural fairness information, so that fair process effects on the outcome judgments are less evident for these people. In other words, people seem much more likely to use fairness judgments as heuristic substitutes for trust when they are uncertain about authority's trustworthiness.

A careful inspection of Fig. 1 reveals that positive and negative trust in and of themselves did not affect the mean level of outcome satisfaction very much. This result might seem counterintuitive, but in the present context it is not unreasonable that positive and negative trust should have little effect on outcome judgments. Tyler et al., (1997; Tyler \& DeGoey, 1996; Tyler \& Lind, 1992), for example, have shown that valenced trust is more important for attitudes and behaviors that have a longer term horizon (e.g., willingness to comply) than variables such as (probably immediate) outcome satisfaction. The trust certainty manipulation appears to have been successful: The manipulation-check findings that were presented in the Van den Bos, Wilke, and Lind (1998) article reveal that positive and negative trust information did in fact affect trust perceptions as well as voluntary compliance with the authority's decisions. Our positive and negative trust information was therefore perceived as intended and was successful at affecting some well-specified variables. Most important for the present discussion, the findings summarized in Fig. 1 reveal that it may sometimes be more valuable to focus on the distinction between known versus unknown trust than on positive versus negative trust. Focusing on the certainty distinction yields insights into the psychology of social justice and trust that previous research, which has focused on the valence distinction, has missed.

It should also be noted that similar effects of certainty about trust also can be found in other settings: In a survey of parents who were interviewed about an 
organization that was responsible for their children's day care, Van den Bos, Van Schie, and Colenberg (in press) found that when respondents were uncertain about the organization's trustworthiness, their judgments of the organization's reliability were more strongly affected by their perceptions of the organization's procedures than were the judgments of respondents who had indicated that they had favorable (and presumably more certain) information about the organization's trustworthiness. These results are in correspondence with those of the experiment presented above and suggest that our line of reasoning also holds in domains quite different from the psychology laboratory. Future research should investigate other domains of social behavior and different operationalizations of trust to find out the generalizability of these effects, but the findings just presented yield new insights into the psychology of why fairness matters.

The findings discussed here provide a good example of one basic phenomenon we want to focus on in this chapter: enhanced attention to, or use of, fairness information under conditions of high uncertainty. In this instance, the study shows that people care more about fairness, and especially procedural fairness, when they are uncertain about whether they can trust authorities. Fairness matters less when individuals are certain about authority's trustworthiness. Interestingly, we have seen that, as predicted, fairness matters less both when people know that the authority can be trusted and when they know that the authority cannot be trusted. In accordance with the line of reasoning presented here, this illustrates the important role certainty and uncertainty play in determining when fairness matters to people: When people are uncertain about whether they can trust authorities fairness matters more than when they are certain that the authority either can or cannot be trusted. In short, we found the predicted moderation of fairness effects when the uncertainty concerned an important issue in the social context-the trustworthiness of an authority. In the studies we describe next, we present further evidence for the role of uncertainty in the why of fairness judgments.

\section{B. UNCERTAINTY FOLLOWING REMINDERS OF DEATH}

The experiments by Van den Bos, Wilke, and Lind (1998) focused on the cognitive process that leads people to use fairness less when they have been made more certain - relative to, for example, their situation at the beginning of an experiment-about an authority's trustworthiness. Van den Bos and Miedema (2000) took this idea one step further by hypothesizing that people are more affected by variations in fairness when they are asked to think about things that make them feel uncertain. These authors tried to show that this would substantially advance insights into why fairness matters to people. More specifically, Van den Bos and Miedema focused on a very important antecedent of feelings of uncertainty (cf. McGregor et al., 2001), people's fear of death. In doing so, these authors used terror management theory to derive their hypotheses. 
According to terror management theory (for overviews, see, Greenberg, Solomon, \& Pyszczynski, 1997; Pyszczynski, Greenberg, \& Solomon, 1999; Solomon, Greenberg, \& Pyszczynski, 1991), the fear of death is rooted in an instinct for self-preservation that humans share with other species. Although human beings share this instinct with other species, only humans are aware that death is inevitable. This combination of an instinctive drive for self-preservation with an awareness of the inevitability of death creates the potential for paralyzing terror. Terror management theory posits that this potential for terror is managed by a cultural anxiety buffer, a social psychological structure consisting of things like one's worldview and self-esteem. To the extent that this buffer provides protection against death concerns, reminding individuals of their death should increase their need for that buffer. Thus, reminders of death should increase the need for the protection provided by the buffer and therefore lead to strong negative evaluations of people whose behaviors and beliefs threaten on that worldview and lead to strong positive evaluations of those whose behaviors and beliefs uphold or provide an opportunity to reconstruct the worldview. (For more extensive discussion of terror management theory, see Greenberg et al., 1997; Pyszczynski et al., 1999; Solomon et al., 1991.)

On the basis of terror management theory, Van den Bos and Miedema (2000) argued that participants who are asked to think about their mortality would react more negatively toward violation of norms and more positively toward things that uphold or bolster cultural norms and values. It is reasonable to assume that most people judge unfair procedures to be in violation with cultural norms and values and think of fair procedures as being in correspondence with norms and values of good behavior and conduct (Lind \& Tyler, 1988). Van den Bos and Miedema, therefore, predicted that participants would show stronger fair process effects in mortality salient conditions than in mortality nonsalient conditions.

Van den Bos and Miedema (2000) describe three experiments, but we discuss only the first experiment. In this experiment, the same experimental paradigm was used as in the experiment discussed above (Van den Bos, Wilke, \& Lind, 1998, Experiment 2), with the exceptions described later. In the first part of the instructions, participants were informed that they would participate in the study with another person, referred to as "Other." The participants were told that after the work round the experimenter would divide some lottery tickets between them and the other participant. After the work round, participants were told how many tasks they had completed in the work round, and-to ensure that participants compared themselves to Other-the participants were told that Other had completed an equivalent number of tasks.

After this, the participants were told that before the experimenter divided the lottery tickets between them and Other, they would be asked to answer some questions supposedly unrelated to the experiment and that after they had completed these questions, the experiment would continue. Mortality salience was then manipulated. As in most previous terror management studies, the mortality salient condition was induced by having participants respond to two open-ended questions 
concerning their thoughts and feelings about their death: (1) "Please briefly describe the emotions that the thought of your death arouses in you"; and (2) "Please write down, as specifically as you can, what you think will happen to you as you physically die." After this, these participants were told that by pushing the return button on the keyboard the study would continue. Participants in the mortality nonsalient condition were not asked to write something down; a manipulation which is in correspondence with previous terror management studies (e.g., Greenberg et al., 1990, Study 1; Rosenblatt, Greenberg, Solomon, \& Pyszczynski, 1989, Studies 1-5).

The procedure was then manipulated. In the voice condition, the experimenter asked participants to type in their opinions about the percentage of tickets that they should receive relative to Other. Participants in the no-voice condition were informed that they would not be asked to type such an opinion. Dependent variables and manipulation checks were then assessed. The main dependent variables were participants' positive affective reactions to the way they were treated (i.e., how happy, content, and satisfied participants felt about the way they were treated).

As expected, a significant interaction between mortality salience and procedure was found. Figure 2 graphs this effect. In the mortality nonsalient condition, participants' affective reactions were significantly more positive following an opportunity to voice their opinion than following no such opportunity, but this fair process effect was stronger in the mortality salient condition. Findings of Experiments 2 and 3 of Van den Bos and Miedema (2000) replicate and extend these results (using other operationalizations of procedural fairness and ratings of affect). Thus, as predicted, when people have been thinking about their own mortality they react more strongly to perceived procedural fairness than when they have not been thinking about this subject.

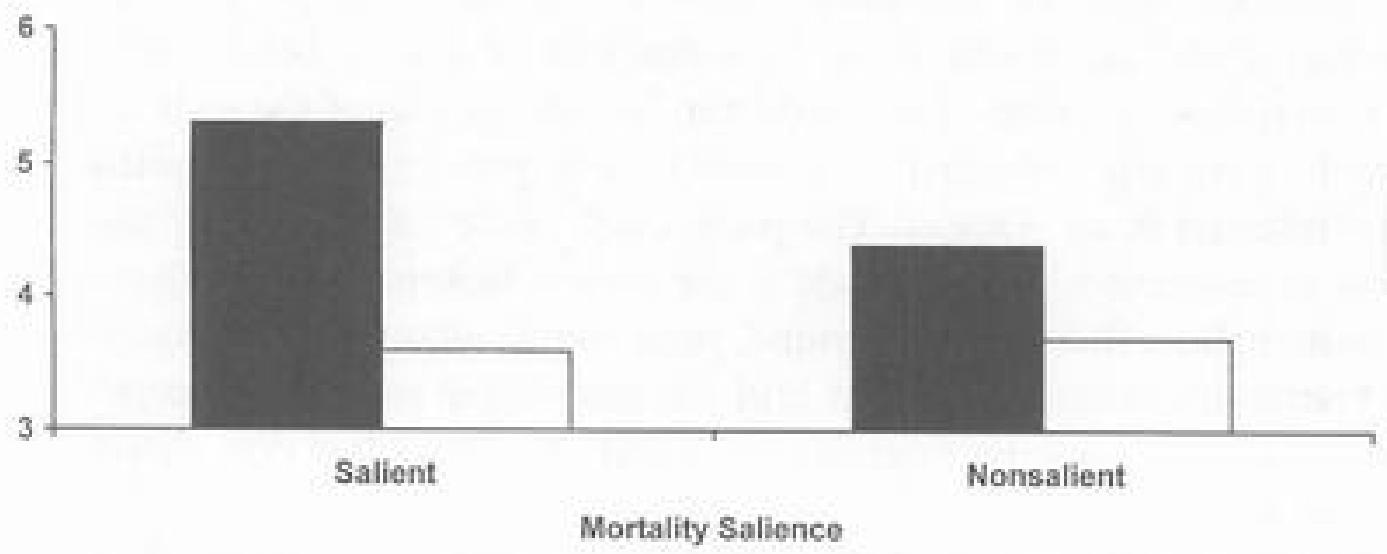

- Volce Procedure a No-Voice Procedure

Fig. 2. Mean positive affective reactions toward treatment as a function of mortality salience and procedure (Van den Bos \& Miedema, 2000, Experiment 1). Means are on 7-point scales with higher values indicating more positive reactions toward treatment. (Van den Bos, K., \& Miedema, J. (2000). Toward understanding why fairness matters: The influence of mortality salience on reactions to procedural faimess. Journal of Personality and Social Psychology, 79, 355-366. Copyright $\otimes 2000$ by the American Psychological Association. Adapted with permission). 
In the context of our current discussion, these findings provide evidence that when people are reminded about aspects of their lives that make them feel uncertain they are in greater need of fairness. This position is strengthened by the results of research (Van den Bos, 2001c) showing that reminding people about their own mortality does indeed make them feel uncertain about themselves and that these feelings of uncertainty explain how people react toward subsequent events. McGregor et al. (2001) also found that mortality salience caused uncertaintyrelated feelings. One of the Van den Bos (2001c) experiments was based on the fact that there is good evidence that state self-esteem is an indicator of the extent to which people are uncertain about themselves (see, e.g., Heatherton \& Polivy, 1991). Therefore, state self-esteem measures were taken as indicators of perceived uncertainty in the experiment, and it was predicted that these measures would reveal that participants' state self-esteem was lower in mortality salient as opposed to nonsalient conditions. Furthermore, it was hypothesized that state self-esteem would mediate the relationship between manipulations of mortality salience and fairness. The results indeed showed that reminding participants about their death lowered their levels of state self-esteem and that state self-esteem mediated participants' reactions to subsequent variations in distributive fairness (participants received an outcome that was equal to the outcome of a comparable other participant or that was worse than the outcome of the comparison other). These findings lend further support to the hypothesis that mortality salience may lead people to become more uncertain about themselves (as indicated by lower levels of state self-esteem; see also McGregor et al., 2001) and hence react more strongly to variations in fairness.

In additional research that supports and extends this line of thought, Miedema, Van den Bos, and Vermunt (2000) recently collected data that show that people react more strongly to variations in fairness when their self-image has been threatened (by having them think of situations in which important aspects of their selves were questioned by other people who are very important for them). The findings of these studies show that reminding people of things that threaten their egos (e.g., being judged as not intelligent) leads to stronger procedural fairness effects than does reminding people of events that do not threaten their egos (e.g., being judged as intelligent). These results are in accordance with our suggestion that fairness is more important for people when they are uncertain about important aspects of their lives. It is now time, however, to move to a review of studies that provide very direct evidence that uncertainty is a key antecedent of why fairness matters. These studies are discussed in the next section.

\section{UNCERTAINTY SALIENCE}

Van den Bos (2001a) extended the studies described above by focusing explicitly on uncertainty as a factor in people's reactions to perceived fairness. The findings 
by Van den Bos and Miedema (2000); Van den Bos, 2001c; Miedema, Van den Bos, \& Vermunt, 2000) suggest that when people are reminded of aspects of their lives that lead them to feel uncertain they will react more strongly to variations in fairness. An interesting and potentially important implication of this is that fairness matters especially to people when their uncertainties have been made salient. However, in the Van den Bos and Miedema studies the implication is just that: an implication. The studies showed that mortality salience, which was presumed to increase feelings of uncertainty, is a moderator of fair process effects, but the Van den Bos and Miedema research presented no direct evidence of the importance of uncertainty salience for people's reactions to perceived fairness.

Van den Bos (2001a) conducted three experiments. Each experiment provides evidence that uncertainty salience itself is an important determinant of people's reactions to perceived fairness. We discuss here only the first experiment in the series. In this experiment, the same setup was used as in Van den Bos and Miedema (2000, Experiment 1). Instead of a mortality salience manipulation, however, uncertainty salience was manipulated directly. Participants in the uncertainty salient condition were asked two questions that solicited participants' thoughts and feelings of their being uncertain: (1) "Please briefly describe the emotions that the thought of your being uncertain arouses in you"; and (2) "Please write down, as specifically as you can, what you think physically will happen to you as you feel uncertain. ${ }^{4}$ Participants in the uncertainty nonsalient condition were asked two questions that were similar in format, but did not remind participants of their uncertainties (see Van den Bos, 2001a): (1) "Please briefly describe the emotions that the thought of you watching TV arouses in you"; and (2) "Please write down, as specifically as you can, what you think physically will happen to you as you watch TV." As in Van den Bos and Miedema (2000, Experiment 1), the fairness manipulation varied whether participants received an opportunity to voice their opinions about the percentage of tickets that they should receive relative to the other participant. The main dependent variables were participants' negative affective reactions to their treatment in the experiment (i.e., how disappointed and sad participants felt about the way they were treated).

Following the line of reasoning we are advancing in this chapter, participants' reactions should be influenced more strongly by perceived fairness in the uncertainty salient conditions than in the nonsalient conditions. In fact, this prediction was supported by a significant interaction between uncertainty salience (salient vs nonsalient) and procedure (voice vs no voice). Figure 3 diagrams this effect. As expected, the effect of the procedural fairness manipulation was stronger in the uncertainty salient condition than in the nonsalient condition.

\footnotetext{
${ }^{4}$ Two judges coded whether the answers that participants wrote down had anything to do with death. As in the experiments by Miedema, Van den Bos, and Vermunt (2000), the judges agreed that answers had nothing to do with death. Thus, as expected, death-related thoughts cannot explain the findings reported in Van den Bos (2001a) and Miedema et al. (2000).
} 


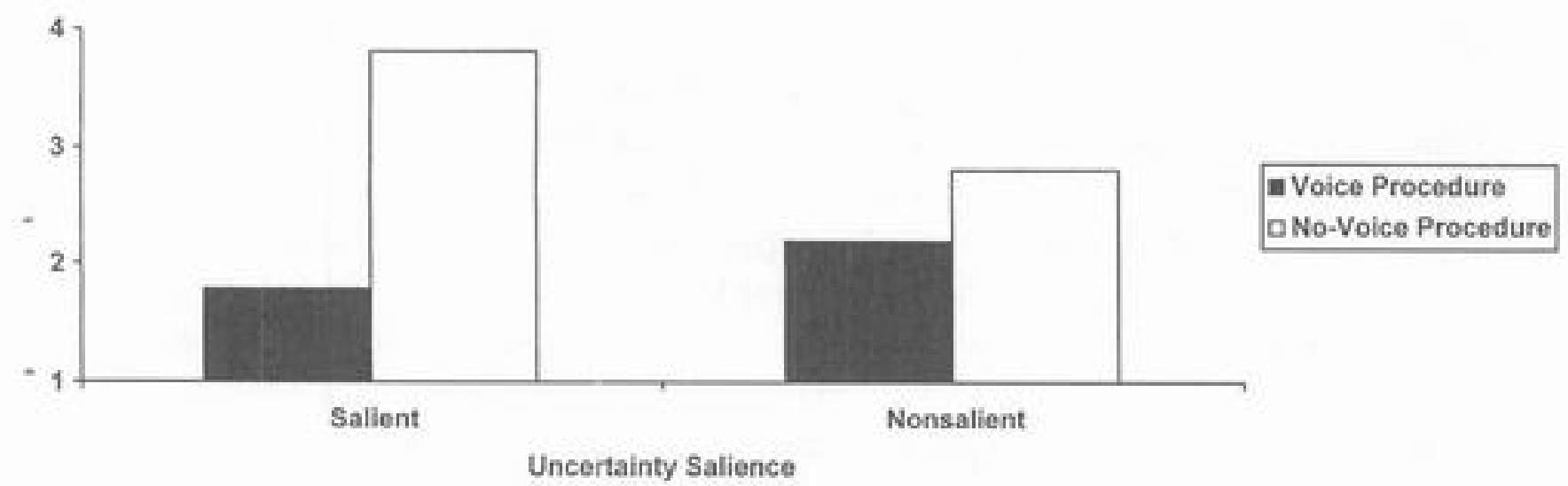

Fig. 3. Mean negative affective reactions toward treatment as a function of uncertainty salience and procedure (Van den Bos, 2001a, Experiment 1). Means are on 7-point scales with higher values indicating more negative reactions toward treatment. (Van den Bos, K. (2001a). Uncertainty management: The influence of uncertainty salience on reactions to perceived procedural faimess. Journal of Personality and Social Psychology, 80, 931-941. Copyright 22001 by the American Psychological Association. Adapted with permission.)

Findings of Experiments 2 and 3 of Van den Bos (2001a) replicate and extend these results (using other operationalizations of uncertainty salience, procedural fairness, and ratings of affect). ${ }^{5}$ Thus, data from three experiments show that uncertainty salience influences reactions to perceived fairness: Asking people to think about their uncertainties leads to stronger effects of perceived fairness on affective reactions to treatment. These findings reveal that fairness matters more to people when they focus on uncertain aspects of their lives. Thus, these findings tell us something that is very fundamental to the point we are trying to make in this section: Fairness has particularly strong effects for people when they have been thinking about issues that are related to their uncertainties. This in turn suggests a novel answer to the question posed earlier about why fairness matters so much to people: It may well be the case that fairness is attended to and fair situations are sought out because fairness may provide protection against things people are uncertain about and/or because it makes uncertainty more tolerable. In other words, fairness is important for people because they use fairness judgments in processes of managing uncertainty,

\section{OTHER STUDIES}

The findings reviewed above are important because they suggest that fairness matters to people because fairness judgments give them an opportunity to manage

SIn the nonsalient condition of Van den Bos (2001a, Experiment 1), the fair process effect did not reach conventional levels of significance, $F(1,73)=2.30, p<.07$ (one-tailed). However, in a followup experiment (Van den Bos, 2001a, Experiment 3), statistically significant effects were found in the nonsalient condition on positive affective reactions toward treatment, $F(1,156)=45.54, p<.001$ (one-tailed). 
their uncertainty about important life events or issues. A study related to this proposition is reported by See (2000). She argued that in many public policy contexts people have insufficient knowledge to know which policy they should support. See proposed that fairness matters more when people feel they have insufficient topical knowledge or information about subject matters important in the issue they face. This led her to predict that fairness judgments would have greater impact on public policy attitudes for individuals who have low subject matter knowledge than for those with high knowledge. In a study of acceptance of new environmental regulation policy, See hypothesized that those who felt they had low knowledge about environmental issues would rely heavily on their perceptions of the fairness of the policy-making body in deciding policy acceptance, whereas fairness would have little or no effect on those who felt they had high knowledge about these issues. See's survey data showed that respondents with low knowledge of environmental matters based their support for a proposed environmental policy in North Carolina on their perceptions of procedural fairness and that individuals with high knowledge were not influenced by perceptions of procedural fairness, relying more on their own subject matter knowledge when evaluating the policy issue. In correspondence with the studies described above, the See study shows that fairness matters more under conditions of information uncertainty.

Quite a number of organizational studies have shown strong fairness effects associated with changes in corporate practices, policies, or structure-changes that are likely to provoke considerable uncertainty about what one's work life will be like in the future. The use of fair process has been found to be associated with acceptance of innovations such as the use of new information or control systems (Eddy, Stone, \& Stone-Romero, 1999; Kidwell \& Bennett, 1994), the introduction of new management structures (Kirkman, Shapiro, Novelli, \& Brett, in press), the institution of smoking bans (Greenberg, 1994), and other significant changes in working policies or conditions (Daly \& Geyer, 1994; Parker, Bales, \& Christensen, 1997). Conceptually similar findings are seen in the results of studies by Brockner and his colleagues (Brockner, Grover, Reed, DeWitt, \& O'Malley, 1987; Brockner, Konovsky, Cooper-Schneider, Folger, Martin, \& Bies, 1994; for a review, see Brockner \& Greenberg, 1990) which show strong justice effects in the context of layoffs, a situation that perhaps raises the greatest uncertainty in organizational contexts. None of these studies have compared the effects of fair treatment at these times to those at more normal (and less uncertain) periods in the life of the worker and the organization, but some organizational scholars (e.g., Cobb, Wooten, \& Folger, 1995; Kim \& Mauborgne, 1997) have suggested that fairness is especially important when there is turmoil and uncertainty in the workplace.

There is, however, one very recent study that shows stronger fairness effects at times of uncertainty than during more normal work times. Lind et al. (2000) studied the behavior of terminated workers as a function of the fairness of their treatment at termination and their treatment during the course of employment. The line of reasoning we are advancing here suggests that, notwithstanding the fact 
that treatment at termination involves a much more limited "sample" of treatment experiences than does treatment over the whole course of employment, treatment at termination will be a more powerful determinant of posttermination attitudes and behaviors. This is because, as we noted above, uncertainty is probably at its greatest during layoffs or firings. Lind et al. found much stronger impact of the fairness of treatment at termination on subsequent behavior-in this case the filing of wrongful termination claims - findings that are quite congruent with our uncertainty hypothesis.

Similar findings are seen in nonorganizational contexts. Van den Bos, Bruins, Wilke, and Dronkert (1999) found that people appear to use perceptions of procedural unfairness to ward off potential threats to themselves (see also Gilliland, 1994). Hafer (2000) has shown, using a Stroop color-naming task, that people react to personal threat by attending to justice beliefs, and these results, we argue, corroborate the hypothesized psychological processes. (We return to this point under Section VII, where we discuss the relationship between our model and other fairness theories.) All of these findings converge on the same basic proposition: Interest in fairness increases substantially in the presence of any number of factors that increase uncertainty about one's physical or social context.

The question of why fairness matters to people is a challenging one that has fascinated and puzzled philosophers and social theorists for centuries. In the current section, we have shown that people seem to make the greatest use of fairness information when they are faced with uncertainty, and we have argued that fairness is sought in this situation precisely because it provides a way to manage uncertainty. As we discuss in greater detail later, when a person feels that things are fair, uncertainty is less vexing. In the next two sections we try to show that uncertainty also is important in the process of forming fairness judgments.

\section{Uncertainty and the How of Fairness Judgments, Part 1: Information Uncertainty Leads to Substitution Processes}

In the next several sections of the chapter we argue that not only does uncertainty stimulate an interest in fairness, but it also drives some specific cognitive processes in the construction of fairness judgments. To put it differently: Uncertainty is important not only for why fairness matters (as was discussed in the previous section), but also for how fairness judgments are formed. Our approach here is driven by the literature on human judgment under uncertainty (e.g., Kahneman et al., 1982) and by the functional approach to the cognitive dynamics of fairness that characterizes our earlier work on fairness heuristic theory (e.g., Lind, 2001; Van den Bos, 2001b; Van den Bos et al., 2001). We predict here that the way people form fairness judgments works in service of the use of these judgments to manage uncertainty, and, as we note later, we find empirical support for this prediction. 
If we want to understand what people judge to be fair we have to consider how uncertainty-related issues affect the fairness judgment process. In the current section, we argue that in the process of forming fairness judgments, people tend to look first for fairness information that is most relevant in the particular situation in which they find themselves. However, it is not uncommon that people lack information about the most relevant fairness issues. We describe research findings that show that in these information-uncertain situations people start using other information-as heuristic substitutes - to assess what is fair. We have labeled this effect the fairness substitutability effect. People substitute one type of fairness information for another, we suggest, to avoid uncertainty about whether they are being treated fairly. It would make little sense, after all, to use fairness as a way to manage uncertainty (cf. the previous section) unless there was a ready psychological solution to the problem of uncertainty about fairness. We show that the substitutability effect gives unique insights into how people form judgments of outcome and procedural fairness under conditions of information uncertainty.

\section{A. SUBSTITUTABILITY EFFECTS ON OUTCOME FAIRNESS JUDGMENTS}

In a 1997 article with Riël Vermunt and Henk Wilke, we set out to try to investigate how judgments of outcome fairness are formed (Van den Bos, Lind, et al., 1997). Probably the most well-known and the most widely accepted answer to the question of how people decide whether their outcome is fair or unfair has been provided by equity theory (e.g., Adams, 1965; Walster, Berscheid, \& Walster, 1973; Walster, Walster, \& Berscheid, 1978). In essence, equity theory proposes that people judge an outcome as fair when their own outcome-to-input ratio equals some comparative or referent outcome-to-input ratio. This process is often driven by social comparison with others' outcomes and inputs such that people judge their outcome as fair when the ratio of their own inputs and outcomes equals the ratio of inputs and outcomes of comparison others (Messick \& Sentis, 1983). Equity theory and other related conceptions of justice - such as relative deprivation theory (Crosby, 1976; Stouffer, Suchman, DeVinney, Star, \& Williams, 1949) and the distributive justice conceptions of Blau (1964), Deutsch (1975, 1985), and Homans (1961) -all emphasize the importance of social comparison information in the process of evaluating outcomes. As Messick and Sentis (1983) note, a central theme in the literature on outcome fairness is that the comparison of a person's outcome with those of comparison others influences the person's beliefs about the fairness or justice of his or her own outcome.

Equity theory has received wide support in social and organizational studies. In fact, some articles in the 1976 volume of the Advances in Experimental Social Psychology even went so far as to argue that equity ratings are the most important type of fairness judgment (see Berkowitz \& Walster, 1976). Thus, equity theory has 
been very influential. But as we noted in the 1997 article, one of its basic propositions is that in order to judge whether an outcome is fair, people have to know what outcomes comparison others have received. The Van den Bos, Lind, et al. (1997) article began by asking whether people always know the outcomes of others, as most theorizing on equity theory assumes they do (for overviews, see Adams, 1965; Messick \& Sentis, 1983; Walster et al., 1973, 1978). We argued that they frequently do not. For instance, in everyday life we often do not know the salaries of the people with whom we work, and even if we do, we may not have a good idea of their contributions. If, as we believe, social comparison information about outcomes frequently is not available, then in everyday life the issue of how people form judgments of outcome fairness is more complicated than equity theory suggests.

Using this reasoning led us to predict substitutability effects in the fairness judgment process. We proposed that when information about outcomes of others is not available, people would start using other fairness-relevant information that is available. But what information is available? We suggested that procedural information is frequently present, even in situations where others' outcomes or contributions are unknown. Thus, in many situations people may turn to the fairness of procedures to determine how to judge their outcome, using procedural fairness as a heuristic substitute to judge the fairness of their outcome. Therefore, in situations where a person only knows his or her own outcome but not other equity-relevant information, we predicted a fair process effect: People would judge their outcome to be more fair following a fair rather than an unfair procedure.

However, we also reasoned that when a person does have enough information to form an equity judgment-when, for example, information is available about the outcome of a comparable other person-the person making the fairness judgment will use this social comparison information as a basis for forming outcome fairness judgments. Therefore, we expected less strong fair process effects in situations where a person knows what outcome the referent other received. When people had social comparison information about outcomes there would be less need for procedural fairness to serve as a heuristic substitute in the process of forming judgments of outcome fairness.

The results of two studies, one scenario experiment and one experiential experiment, corroborated our line of reasoning. In the present chapter, we discuss only the second experiment. In it, we used the same paradigm as in the Van den Bos and Miedema (2000) study described earlier in the chapter. After participants had completed the work round, they were told how many tasks they had completed in the work round, and - to ensure that participants felt they could compare their contributions to those of the Other-the participants were told that Other had completed an equivalent number of tasks.

After this, our experimental manipulations were induced. First, the procedure was manipulated. In the voice condition, the experimenter asked participants to type in their opinions about the percentage of tickets that they should receive relative to Other. Participants in the no-voice condition were informed that they 
would not be asked to type such an opinion. The participants then received three lottery tickets. This was followed by the manipulation of the outcome of the other participant. In the Other-better condition, the participant was informed that Other received five tickets. In the Other-worse condition, participants were informed that Other received one ticket. In the Other-equal condition, participants were told that Other received three tickets. In the Other-unknown condition, participants were told nothing about the number of tickets Other received. After this, we assessed how fair participants considered the three lottery tickets that they received.

First of all, it should be noted that participants who received an equal number of lottery tickets judged their outcome to be more fair than participants who received more tickets than the other participant and also to be more fair than participants who received fewer tickets than the other participant. In addition, we found that the outcome fairness judgments of participants who received more tickets did not differ from judgments of participants who received fewer tickets. These findings are congruent with equity theory. More interesting, in the context of the current discussion, is the fact that participants' judgments of outcome fairness also showed a significant interaction effect between procedure and the outcome of the other participant. Figure 4 shows this effect. In accordance with our predictions, participants who did not know the outcome of the other participant judged their own outcome to be significantly more fair when they had received an opportunity to voice their opinion than when they received no such opportunity. Furthermore, in the conditions in which participants knew the outcome of the other participant, judgments did not differ significantly as a function of whether participants were or were not allowed a voice in the outcome award process.

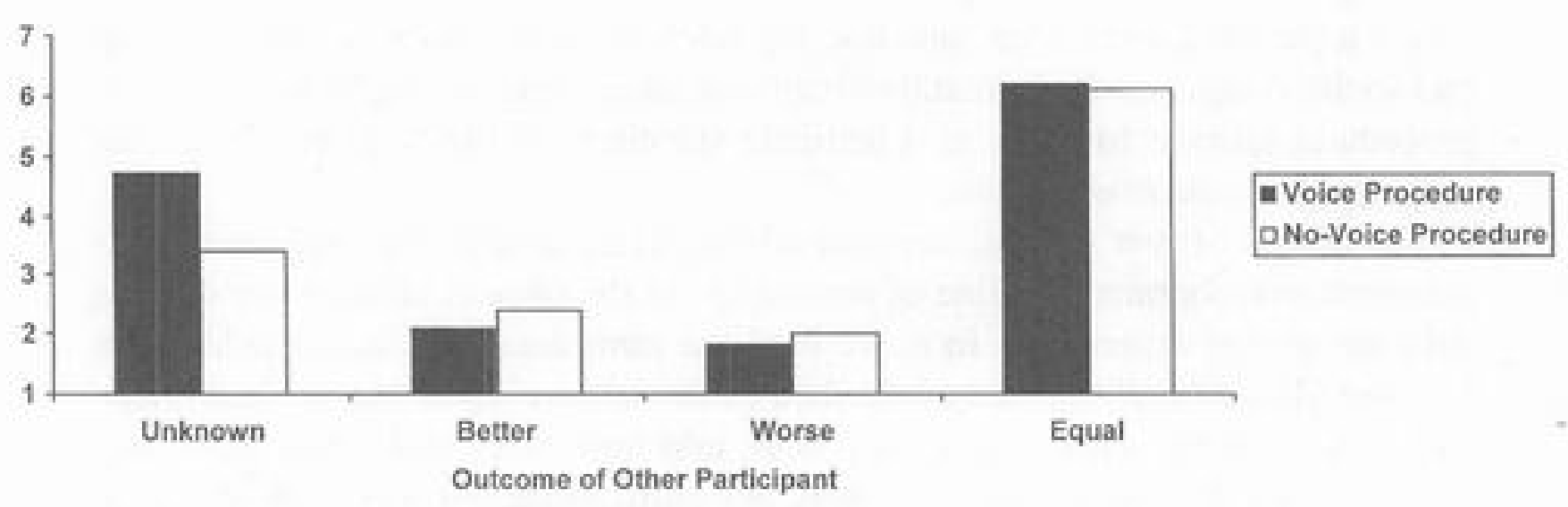

Fig. 4. Mean outcome faimess judgments as a function of outcome of other participant and procedure (Van den Bos, Lind, Vermunt, \& Wilke, 1997, Experiment 2). Means are on 7-point scales with higher values indicating more positive ratings of outcome faimess. (Van den Bos, K., Lind, E. A., Vermunt, R., \& Wilke, H. A. M. (1997). How do I judge my outcome when I do not know the outcome of others? The psychology of the fair process effect. Joumal of Personality and Social Psychology, 72. 1034-1046. Copyright 1997 by the American Psychological Association. Adapted with permission). 
These findings strongly support our line of reasoning: When people are uncertain about outcomes of social comparison others they indeed use procedural fairness - as a heuristic substitute - to assess how to react to their own outcome (yielding fair process effects on people's judgments of outcome fairness). But people rely less on procedural information when they are certain about the outcome received by comparison others (resulting in nonsignificant fair process effects). This shows that, to understand the fairness judgment process, it is important to take into account conditions of information certainty or uncertainty. The findings also show an important limitation of equity theory: Equity theory describes what information people need to judge their outcome as fair or unfair, but it does not deal with the issue of what happens when important information is missing. The results of Van den Bos, Lind, et al. (1997) suggest that classifying information conditions is an important precondition before we as scientists and practitioners can say whether the processes proposed by equity theory are operating (Van den Bos, 2001b). More generally, the findings suggest that fairness judgments are formed in quite different ways depending on whether people are uncertain about the most relevant fairness information (in the case of outcome fairness judgments: information about inputs and outcomes of self and one or more comparison others; cf. Messick \& Sentis, 1983).

In a later article (Van den Bos, Wilke, Lind, \& Vermunt, 1998) we expanded on these findings and argued that the substitutability process occurs not just when perceivers lack strong social comparison information of the sort present in the other-outcome-known conditions of the Van den Bos, Lind, et al. (1997) studies. In other situations where it is reasonable to suppose that perceivers are uncertain about important elements needed to judge outcome fairness, they rely more strongly on procedural information in the process of judging outcome fairness, and hence their outcome fairness judgments are more strongly affected by procedural information.

In the Van den Bos, Wilke, Lind, and Vermunt (1998) article, we tested this line of reasoning by comparing the strength of procedural effects in the presence of social comparison-based versus expectation-based information. In the second study presented in the article, all participants received three lottery tickets, and this outcome was manipulated to be better than expected (participants had expected to receive one ticket), worse than expected (five tickets had been expected), equal to the outcome of a comparison other (Other received three tickets), better than the outcome of the comparison other (Other received one ticket), or worse than the outcome of the comparison other (Other received five tickets). The second independent variable was the presence or absence of an opportunity to voice an opinion (cf. Van den Bos, Lind, et al., 1997). The primary dependent variables included participants' outcome fairness judgments.

There is evidence that expectation-based reference points may be sufficiently weak or ambiguous that fair process effects will occur (e.g., Austin, McGinn, \& Susmilch, 1980; Blau, 1964). On the basis of this, we argued that knowing that your 
outcome is equal to, better than, or worse than the outcome of a comparison other provides more relevant information and a more diagnostic reference point regarding how to respond to your outcome than knowing only that your outcome is better or worse than expected. Following the fairness substitutability proposition, this implies that people who receive an outcome that is better or worse than expected will use other information-such as procedural information-more than people who receive an outcome that they know is equal, better, or worse than that of the comparison other. Therefore, we predicted an interaction between procedure and outcome such that outcome fairness judgments would show strong effects of procedural fairness when outcomes were better or worse than expected, whereas less strong fair process effects would appear when outcomes were equal to, better than, or worse than the outcome of a comparison other. The findings were supportive of this prediction (for details, see Van den Bos, Wilke, Lind, \& Vermunt, 1998).

Skitka (in press) has replicated the Van den Bos, Lind, et al. (1997) findings using different operationalizations of outcome certainty. In the Van den Bos, Lind, et al. experiments, certainty about outcome fairness was manipulated by giving participants either complete or incomplete information about social comparisonbased equity. Skitka has found comparable effects by making a distinction between situations in which people have a very clear a priori sense of fair outcomes (a moral mandate) and situations in which they do not have a strong moral mandate. Her findings showed stronger effects of procedure on outcome evaluations among respondents who had no clear a priori sense of which outcomes were fair or unfair than among those who did have strong moral mandates.

\section{B. SUBSTITUTABILITY EFFECTS ON PROCEDURAL FAIRNESS JUDGMENTS}

Extending on the findings reviewed above, Van den Bos (1999) investigated whether the substitutability effect could shed new light on the question of how judgments of procedural fairness are formed. In contrast to the studies discussed in the previous paragraphs, Van den Bos focused on the reverse effect: the positive effect of perceived outcome fairness on fairness judgments of procedure- what might be termed a fair outcome effect. Van den Bos predicted and found a fair outcome effect that was patterned in such a way as to show that there are important psychological implications of making a distinction between what was called explicit and implicit no-voice conditions.

This distinction requires some additional explanation. Following Folger's early research (e.g., Folger, 1977; Folger et al., 1979), studies on procedural justice have frequently investigated how people react to being allowed an opportunity to voice their opinion versus not being allowed such an opportunity. This is now probably the most used manipulation of procedural justice (e.g., Brockner et al., 1998; 
Lind et al., 1990; Lind \& Tyler, 1988; Tyler \& Lind, 1992; Tyler, Rasinski, \& Spodick, 1985; Van den Bos, Vermunt, \& Wilke, 1996).

The Van den Bos (1999) article sought to make a distinction between two types of no-voice procedures that exist in everyday life and that have been used in previous research studies. One type of no-voice procedure has been used in studies by Folger (1977) and Lind et al. (1990). In both these studies, only participants who ultimately were allowed voice were informed about a possibility that participants could have an opportunity to voice their opinion about an important decision the experimenter was going to make. After being told that voice was possible, these participants were informed that they would in fact have an opportunity to exercise voice. Participants in the no-voice condition were not informed about the possible voice opportunity and hence were not allowed a voice only implicitly. In the Van den Bos (1999) article this was labeled as an implicit no-voice procedure. In other research a different type of no-voice procedure was used (e.g., Brockner et al., 1998, Study 5; Hunton, Hall, \& Price, 1998; Van den Bos, Lind, et al., 1997; Van den Bos et al., 1996; Van den Bos, Wilke, \& Lind, 1998; Van den Bos, Wilke, Lind, \& Vermunt, 1998): In these studies participants in both the voice and novoice conditions were informed that there was a possibility that participants could get an opportunity to voice their opinion about a decision the experimenter was going to make. Participants in the voice conditions were then told that they would receive voice, whereas participants in the no-voice conditions were informed that they would receive no opportunity to voice their opinion. This latter procedure was called an explicit no-voice procedure.

Previous research had made no distinction between implicit and explicit no voice, and in previous articles (including our own articles) these two types of novoice procedures had been treated as if they were one and the same thing. The Van den Bos (1999) article tried to show, however, that making this distinction is not only methodologically important but that it also may help to further insights into how people form judgments of procedural fairness. On the basis of the substitutability proposition, Van den Bos argued that when information about procedure is not available (as in the case of implicit no-voice procedures), people will be uncertain as to how they should judge the procedure, and they therefore will use the fairness of their outcome to assess how to respond to the procedure. As a result, the procedural fairness judgments of these people were expected to show strong effects for the fairness of the outcome. However, persons who are explicitly denied voice have explicit information about procedure and hence have less need to rely on outcome information, yielding weaker fair outcome effects on procedural fairness judgments.

The second study in the Van den Bos (1999) article was an experiment that was comparable to those reviewed above. In the voice condition, the experimenter asked participants to type in their opinion about the percentage of tickets that they should receive relative to the other participant. Participants in the explicit no-voice condition were informed that they would not be asked to type their opinion about 
the percentage of tickets that they should receive relative to the other participant. In the implicit no-voice condition, participants received no information about voice or no-voice procedures (and hence implicitly received no voice opportunity). After this, participants received three lottery tickets, and they were told that the other participant received either three tickets (Other equal condition) or five tickets (Other better condition). The main dependent variable, for our purposes here, was the participants' procedural fairness judgments.

Participants' procedural fairness judgments showed significant effects for procedure, outcome, and the interaction between procedure and outcome. The main effect of procedure revealed that perceptions of procedural fairness were most positive when participants had received voice, moderately positive when participants implicitly had received no voice, and least positive when participants explicitly had received no voice. The main effect of outcome indicated that participants who received an outcome that was equal to the other participant's outcome judged the procedure to be more fair than participants who received an outcome that was worse than the other participant's outcome. More interestingly, the interaction effect qualified these effects. Figure 5 shows the interaction effect. As expected, there were strong, significant fair outcome effects on participants' procedural fairness judgments in the implicit no-voice condition, revealing that participants judged their procedure to be more fair when their outcome was equal to rather than worse than the outcome of the other participant. In the explicit no-voice and the voice conditions, weaker, nonsignificant effects of outcome were found, indicating that in those conditions procedural fairness judgments did not differ as a function of the other participant's outcome.

These findings show that it is important to make a distinction between implicit and explicit no-voice procedures because these two variations of no-voice

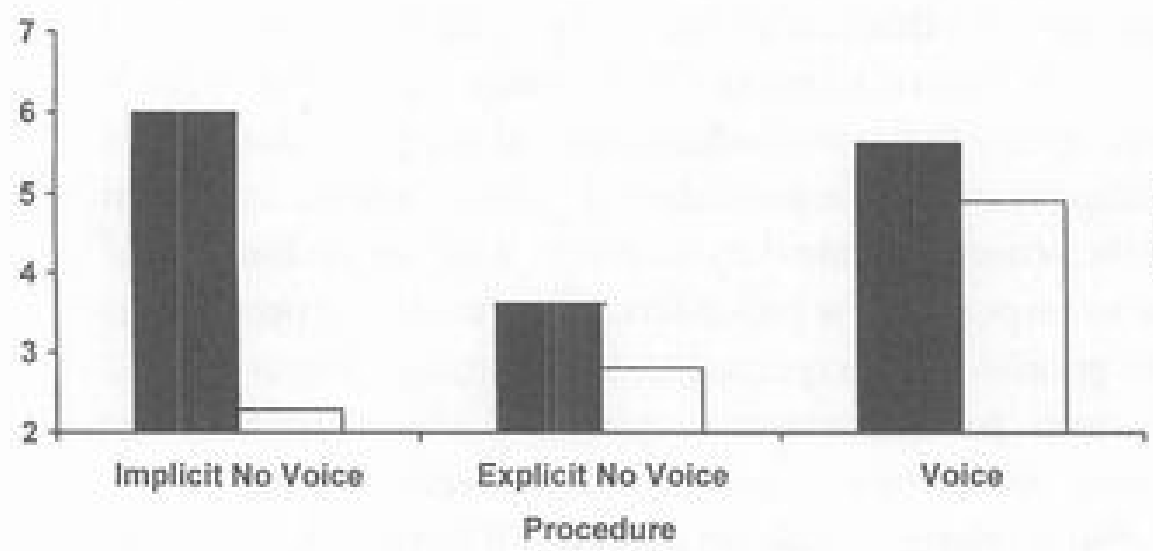

n Outcome of Other Participant Equal $\square$ Outcome of Other Participant Better

Fig. 5. Mean procedural fairness judgments as a function of procedure and outcome of other participant (Van den Bos, 1999, Experiment 2). Means are on 7-point scales with higher values indicating more positive ratings of procedural fairness. (Van den Bos, K. (1999). What are we talking about when we talk about no-voice procedures? On the psychology of the fair outcome effect. Joumal of Experimental Social Psychology, 35, 560-577. Copyright $\odot 1999$ by Academic Press, an imprint of Elsevier Science. Adapted with permission). 
manipulations invoke quite different fairness judgment processes. When information about procedure is not available - as is the case in the implicit no-voice conditions - people may find it difficult to decide how they should judge the procedure. Under such conditions of uncertainty about procedural information, people will use the fairness of their outcome, as a heuristic substitute, to determine how to respond to the procedure. As a result, the procedural fairness judgments of these people show strong fair outcome effects. However, under conditions of greater certainty about procedural fairness (such as when individuals explicitly have been denied voice or have received voice), people have less need to rely on outcome information, yielding weaker fair outcome effects on their procedural fairness judgments. This suggests that uncertainty about procedural information is a key moderator of how procedural fairness judgments are formed.

Now that Van den Bos (1999) has identified that important differences within no-voice procedures exist, future research might do well to focus on other rules of procedural justice and consider how fairness reactions to these rules might differ depending on whether the rule is explicitly or implicitly violated. Leventhal (1980), for example, suggests that procedural justice involves such qualities as lack of bias, representation, correctability, consistency, and other qualities. It is interesting to note here that there is some evidence suggesting that when information about biased procedures is absent (as opposed to present) people rely more on outcome information (Daly \& Tripp, 1996). Van den Bos and Lind (2001) found that there are conditions under which the substitutability process works across people and justice dimensions in that information about another person's fair or unfair treatment may have more impact if one does not yet know whether one's own treatment will be fair. Although not cast in certainty about procedural fairness terms, the results of research by Bobocel, Son Hing, Davey, Stanley, and Zanna (1998) indicate that prior values and beliefs associated with fair treatment can have an important impact on policy preferences.

In the studies that we discussed earlier in this section, the effects of information about a procedure on outcome fairness judgments were explored (Van den Bos, Lind, et al., 1997; Van den Bos, Wilke, Lind, \& Vermunt, 1998). In most of these fair process studies, we focused on the characteristics, or the absence, of outcome information and on the possibility of procedural fairness acting as a heuristic substitute under conditions of uncertainty about outcome information. The studies by Van den Bos (1999), Daly and Tripp (1996), and others expand the line of reasoning to the reverse effect: the influence of outcome information on procedural fairness judgments. Collectively, all these studies show that information about either type of fairness - outcome or procedural — can act as a substitute for missing information about the other. In each case, people are substituting one type of fairness information for another when the more relevant information is not available. This suggests a second way that uncertainty impacts the psychology of fairness judgments. When people are forming fairness judgments they are 
involved in a special type of uncertainty management: They are trying to resolve the uncertainties they encounter in the fairness judgment process. What is especially interesting about the findings presented here is that they show that information uncertainty internal to the fairness judgment process leads to strong fairness substitutability effects on fairness judgments. Future research might profitably explore the hypothesis that greater substitutability effects are expected in situations that generate general uncertainty external to the fairness judgment process (such as situations that induce uncertainty salience; cf. Van den Bos, 2001a). In the next section, we argue that-in addition to substitutability effects-another important consequence of the use of fairness judgments for uncertainty management is that it may lead to primacy effects in the construction of fairness judgments.

\section{Uncertainty and the How of Fairness Judgments, Part 2: Uncertainty Leads to Primacy Effects}

Conditions of uncertainty foster anchoring effects (e.g., Tversky \& Kahneman, 1974), and Van den Bos, Vermunt, and Wilke (1997) took this fact as a starting point to study anchoring effects, and particularly primacy effects, on procedural and distributive fairness judgments. Van den Bos, Vermunt, and Wilke argued that because ceding authority to another person provides an opportunity for exploitation, people frequently feel uncertain about their relationship with authorities whom they do not know or with whom they have not interacted before. The theoretical analysis put forward by these authors suggested that a key approach to resolving this uncertainty is to refer to impressions of fairness to decide whether the authority is trustworthy, will be neutral, and will accord one appropriate standing (cf. Tyler \& Lind, 1992; Van den Bos, Wilke, \& Lind, 1998). Van den Bos, Vermunt, and Wilke (1997) argued that an implication of this cognitive process is that the moment people enter this uncertain situation they start searching for information on which they can build fairness judgments. Furthermore, on the basis of fairness heuristic theory (e.g., Lind, 1992), the authors argued that once people have established fairness judgments, perceived fairness serves as a heuristic for interpreting subsequent events. Therefore, they suggested, fairness judgments are more strongly influenced by information that is available in an earlier stage of interaction with the authority than by information that becomes available later.

Van den Bos, Vermunt, and Wilke (1997) were intrigued by frequently replicated survey findings that show that procedural justice factors explain more variance in fairness judgments than distributive justice factors (e.g., Folger \& Konovsky, 1989; Lind et al., 1993; Tyler \& Caine, 1981, Studies 2 and 4; Tyler \& Folger, 1980; Tyler, Rasinski, \& McGraw, 1985). In order to explain these survey findings, Van den Bos, Vermunt, and Wilke explored whether the conditions in which people 
form judgments about procedural and distributive fairness might affect the impact of each fairness dimension. Specifically, they focused on the order in which people receive information about procedure and outcome.

If there is a typical order in which procedural and distributive fairness judgments are formed, it is that in which people receive procedural information before they receive outcome information. For instance, the manner in which a court trial is conducted is typically known before the verdict is rendered. A second type of situation, however, is also possible: People might learn of the outcome before they receive information about the procedure that was followed. For example, suppose a student takes a multiple-choice test. Two weeks later she is informed that she has failed to pass the test, and only 2 months after this she receives information that the professor graded only 10 of the 40 multiple-choice items of her test.

Using this line of reasoning, Van den Bos, Vermunt, and Wilke (1997) argued that when procedural information is available before outcome information becomes available, procedural information will affect people's fairness judgments more strongly than is the case if people receive procedural information after having received outcome information. However, the same logic also suggests that outcome information will affect fairness judgments more strongly when the outcome information comes first. In short, the information that comes first exerts a stronger influence on fairness judgments than information that comes second.

To test these predictions, two studies were conducted; one scenario experiment and one experiential experiment. Again, in the present chapter we discuss only the last experiment because the design and the findings of the two studies were virtually identical. In this experiment, participants were invited to the laboratory to participate in a study on how people make estimations. In all conditions of the experiment, participants received no information about the experimenter's trustworthiness, neutrality, and so on, so all the participants were uncertain about the authority they faced (cf. Van den Bos, Wilke, \& Lind, 1998). The participants were told that they would perform an estimation test consisting of 10 estimation items. Furthermore, the participants were informed that at the end of the experiment they would receive a bonus of 5 Dutch guilders if they succeeded in passing the estimation test. After the participants had completed the estimation test, the manipulations were induced.

In the condition where the participants were informed about the procedure before they received information about the outcome, they first received information about the procedure that was used to assess the outcome of the estimation test: In an accurate procedure condition, the participants were told that the experimenter had graded all 10 estimation items to assess the outcome of the estimation test, and in the inaccurate procedure condition, the participants were told that the experimenter had graded 1 of the 10 estimation items. After this, the participants in this order condition were informed about the outcome of the estimation test: In the favorable outcome condition, the experimenter informed the participants 
that they had succeeded in passing the estimation test. In the unfavorable outcome condition, the participants were informed that they had not succeeded in passing the estimation test.

In the condition where participants were informed about the outcome before they received information about the procedure, they first received information about the outcome of the estimation test: In the favorable outcome condition, the experimenter informed the participants that they had succeeded in passing the estimation test. In the unfavorable outcome condition, the participants were informed that they had not succeeded in passing the estimation test. After this, these participants were informed about the procedure used to assess the outcome of the estimation test: In the accurate procedure condition, the participants were informed that the experimenter had graded all 10 estimation items. In the inaccurate procedure condition, the participants were informed that the experimenter had graded 1 of the 10 estimation items.

After this, participants were asked, among other things, how fair they considered the procedure used to assess the outcome of the estimation test and how fair they considered the outcome of the estimation test. These dependent variables were strongly correlated and yielded similar results (see Van den Bos, Vermunt, \& Wilke, 1997). Figure 6 shows the mean results, collapsed across judgments of procedural and outcome fairness. The findings strongly supported predictions: Both procedural and outcome fairness judgments were more strongly affected by the procedure manipulation when procedural information was available first than when it was available second, and both types of fairness judgments were more strongly affected by the outcome manipulation when outcome information was presented first than when it was presented second. These results suggest that the frequent finding

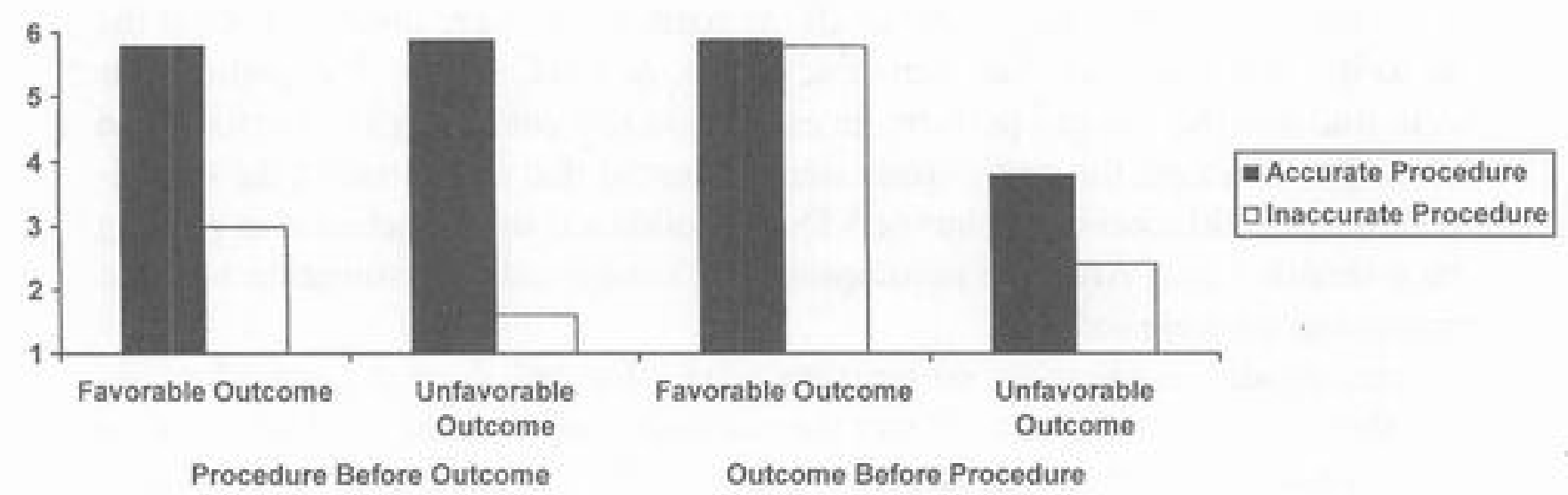

Fig. 6. Mean faimess judgments (collapsed across judgments of procedural faimess and outcome fairness) as a function of procedure, outcome, and order of presentation (Van den Bos, Vermunt, \& Wilke, 1997, Experiment 2). Answers were given on 7-point scales with higher values indicating more positive ratings of procedural fairness and outcome fairness. (Van den Bos, K., Vermunt, R., \& Wilke, H. A. M. (1997). Procedural and distributive justice: What is fair depends more on what comes first than on what comes next. Journal of Personalify and Social Psychology, 72, 95-104. Copyright 81997 by the American Psychological Association. Adapted with permission). 
that procedural information has an advantage in determining fairness judgments in uncertain situations is a phenomenon that has to do with the timing of exposure to procedure versus outcome information. Because people need fairness judgments to guide their behavior in uncertain situations, early information has greater impact than later information. Fairness judgments can be changed by later information, but not as easily as is the case for early information (for more thorough discussion of these processes, see Lind, 1994, 2001; Van den Bos, Vermunt, \& Wilke, 1997).

Van den Bos, Vermunt, and Wilke (1997) showed that whichever type of justice information, whether procedural or distributive, is encountered first in uncertain situations sets the stage for the interpretation of later fairness information. These early fairness judgments provide anchors that are at most only adjusted by later information, including later outcome information. Lind, Kray, and Thompson (2001) have replicated and expanded these findings, showing that, within one type of fairness judgments (procedural fairness), early fairness information has greater impact than later fairness information. Van den Bos, Vermunt, and Wilke (1996) showed that a procedural rule that is available at an early moment in time will affect people's fairness judgment process more strongly than procedural rules that become available at a later moment in time. Boles and Messick (1990) report results similar to those of Van den Bos, Vermunt, and Wilke (1997) in research investigating whether people accept unexpected payment in an ultimatum game when they have not yet been informed about the allocation procedure versus when they have been informed about the procedure. Steiner, Guirard, and Baccino (1999) have collected data that provide corroborative evidence for the hypothesized psychological processes. That is, these authors used an eye-tracker apparatus to collect eye movement data as participants read procedural and outcome information in an experiment, and found, among other things, greater reading of information that was presented first.

A common element in all these studies, we argue, is that uncertainty was held constant at a reasonably high level, ${ }^{6}$ and that the first fairness information encountered was accorded the greatest weight. This implies that people really seem to feel the need to form fairness judgments when confronted with social or personal uncertainty. This again suggests that an important element of the fairness judgment process is uncertainty management: When they are forming fairness judgments, as when they are using fairness judgments, people are busy attempting to manage their feelings of uncertainty, and in doing so they seize on early information to form fairness judgments.

It is well-established in the literature on decision making that conditions of uncertainty foster anchoring effects (e.g., Tversky \& Kahneman, 1974), and the primacy findings that were reviewed here are an important example of one particular type of anchoring effect - assimilation - in the justice domain. Research by

\footnotetext{
${ }^{6}$ Future research should induce different conditions of general certainty and uncertainty and test whether there are indeed stronger primacy effects under conditions of uncertainty.
} 
Van den Bos (in press) provides information on the conditions under which other anchoring phenomena, such as contrast effects, can be found (see also Markovsky, 1988). Van den Bos (in press) focused on the psychology of the fair process effect. Following Stapel and Koomen (2001), Van den Bos argued that when people have received an outcome they usually assimilate their ratings of outcome fairness and affect toward their experiences of procedural fairness. As a result, the ratings show fair process effects. It is also possible, however, that when people have received their outcome they compare and contrast this outcome to the procedure they experienced: Is the outcome better or worse than the procedure? A result of this comparison process may be that contrast effects are found such that higher levels of procedural fairness lead to more negative, not more positive, ratings of outcome fairness and affect. But what determines whether outcome ratings are assimilated or contrasted to perceptions of fair process? Van den Bos's research findings suggest that when comparison goals have been primed (cf. Stapel \& Koomen, 2001), contrast effects can be found: Fair procedures lead to more negative reactions than unfair procedures (for details, see Van den Bos, in press). This suggests another way in which anchoring phenomena may affect fairness evaluation processes. It should be noted here that uncertainty was held constant at a reasonably high level in the Van den Bos (in press) experiment, as in the other studies discussed in this section. Future research should vary general uncertainty and show stronger anchoring effects under conditions of uncertainty.

The findings presented in this section speak both to how fairness judgments are formed and to why fairness matters to people: Under conditions of uncertainty people need fairness judgments more and hence anchoring effects can be expected in the process of forming fairness and other judgments. In the next section, we discuss and integrate the implications of the empirical work on the why and how of fairness judgments that we have been reviewing in the previous sections.

\section{Uncertainty Management by Means of Fairness Judgments}

In this chapter we have argued that the two most basic questions that the social psychology of fairness should try to answer are (1) why do people care about fairness? and (2) how are fairness judgments formed? In this section, we propose that both the why and how of fairness judgments are affected profoundly by processes of uncertainty management. That is, fairness matters to people because it gives them a way to manage their feelings of uncertainty. Furthermore, when they form fairness judgments people are busy resolving uncertainties they encounter within the fairness judgment process. We argue here that this suggests that much of the psychology of fairness can be explained by explicitly referring to processes of uncertainty management. Thus, we are proposing a model of uncertainty management by means of fairness judgments. 
In this section, we discuss the implications of the research findings we have reviewed for why and how people are in need for fairness judgments in an uncertain world. We present important questions for future research and point out how we think these questions could be answered. We formulate propositions concerning the social psychology of justice and fairness and discuss future directions the field may want to take. Finally, we discuss the implications of our model for the social psychology of uncertainty management in general.

\section{A. WHY PEOPLE NEED FAIRNESS IN AN UNCERTAIN WORLD}

We began our discussion of the link between uncertainty and fairness with a set of research findings that show that when people are uncertain whether an authority can be trusted, they will rely heavily on their perceptions of procedural fairness, yielding strong fair process effects. However, when people become certain that the authority can or cannot be trusted, they appear to make less use of procedural fairness information, yielding less strong fair process effects. The implication of these findings is that when people move from uncertainty to certainty, they end up using, and presumably needing, fairness less (Van den Bos, Wilke, \& Lind, 1998). We also described a number of studies that showed that people are affected more by variations in fairness when they are reminded about things that make them feel uncertain. The implication is that moving from relative certainty to uncertainty makes fairness more important for people (Van den Bos, 2001a).

It is important to ask ourselves here whether our line of reasoning suggests that concerns about uncertainty are the only reason, the most important reason, or only one of several reasons that people care about fairness. This is an important question, in part because if it turns out that the concern with fairness can indeed be completely explained in terms of uncertainty, then we could see the entire field of social fairness being reoriented. We think that uncertainty is, at the very least, a very important element of the psychology of fairness because the findings that we have reviewed here all suggest that people need fairness more when they are uncertain about things that are important to them. In fact, in many of the studies fairness effects were minimal in the certain conditions. We think it is reasonable to conclude, therefore, that the findings reviewed in this chapter tell us something very fundamental with regard to the psychology of social fairness: The findings show that, across a wide variety of contexts, fairness is important for people because they use fairness judgments in processes of managing uncertainty.

There is at least one line of research that appears, at first glance, to be at odds with the position we are putting forward here by suggesting that people who feel certain about themselves respond more strongly to variations in perceived fairness than do those who do not feel certain about themselves. Brockner et al. (1998) suggest that high self-esteem individuals are more affected by their perceived level of voice than low self-esteem persons. However, the antecedents driving the 
phenomenon that Brockner et al. are investigating seem to be not uncertainty but rather perceived competence to exercise voice. Most pertinent for the present purposes, the fifth study in the Brockner et al. article consisted of an experimental design in which procedure (voice vs no voice) and participants' beliefs about their capability to provide meaningful input (higher vs lower) were orthogonally manipulated. The results of this study showed that procedure had a greater impact on the satisfaction level of participants who were led to believe that they were more capable of providing meaningful input. Contrast the Brockner et al. findings with a recent study by Vermunt, Van Knippenberg, Van Knippenberg, and Blaauw (2001). These authors operationalized self-esteem by means of a validated self-report questionnaire (a stable social self-esteem version of the Heatherton \& Polivy, 1991, scales; for details, see Vermunt et al., 2001) and found that procedural fairness information was more strongly related to the reactions of low as opposed to high self-esteem respondents. These differential findings may be caused by different operationalizations of self-esteem and fairness (for details, see Brockner et al., 1998; Vermunt et al., 2001).

Future research should explore these, and other, operationalizations of the concepts reviewed in the current chapter and investigated in the articles by Brockner et al. (1998), Vermunt et al. (2001), and the studies reviewed here (e.g., Van den Bos, 2001a). Future research should also study the relationships between uncertainty and concepts such as self-esteem, confidence, and control. This will contribute ultimately to a more refined analysis of the relationship between perceived fairness, uncertainty, and concepts and constructs related to uncertainty. It seems fair to say, however, that at this moment there are relatively more studies that suggest that uncertain persons tend to be more affected by variations in fairness (cf. Van den Bos, 1999, 2001a, 2001c; Van den Bos, Lind, et al., 1997;Van den Bos, Wilke, \& Lind, 1998; Van den Bos \& Miedema, 2000; Van den Bos, Wilke, Lind, \& Vermunt, 1998; Vermunt et al., 2001; see also Skitka, in press, and Brockner, DeWitt, Grover, \& Reed, 1990) than there are studies that suggest that certain persons are more affected by perceived fairness (cf. Brockner et al., 1998).

That the preponderance of studies show stronger fairness effects under uncertainty than under certainty might arguably be due to the cultural milieu of the research. That is - compared to Third World countries, for example - in our Western world extreme levels of uncertainty are less common than are more moderate levels. Maybe fairness is more important under conditions of moderate uncertainty as opposed to extreme uncertainty, explaining why fairness is very important in our Western world. There is, however, little evidence to support this view. It should be noted, for example, that cross-cultural research on fairness typically does not find strong differences between fairness effects between cultures even if they are very different from each other (Lind \& Tyler, 1988; Lind, Tyler, \& Huo, 1997), suggesting that even in cultures with extreme levels of uncertainty fairness concerns are important. Future research should explore, of course, the boundary conditions 
of the psychology of fairness judgments that we are proposing here. Hofstede's (1980) work on cross-cultural differences with regard to uncertainty avoidance may be especially important in this respect.

There are, to be sure, many questions yet to be answered about the use of fairness to manage uncertainty. For example, one could argue that people are always faced with uncertainties but that these uncertainties may vary greatly in importance and level of uncertainty and that this may affect people's reactions considerably. The uncertainty of whether one will like the new "James Bond" movie, for instance, is not the same as uncertainty about layoffs or death, and people probably react differently to these types of uncertainties. Thus, all uncertainties are not the same and cannot be expected to have the same effects. However, the research findings by Van den Bos (2001a) revealed that just asking participants two questions about their being uncertain leads to stronger reactions toward perceived fairness, and the Lind et al. (2000) study of terminated workers showed similar effects for substantial life uncertainty. Thus studies with radically different types of uncertainty converge on the finding that uncertainty plays an important role in the psychology of social fairness. This finding leads us to conclude that fairness is important for people because fairness judgments are one of the key ways that people use to approach the problem of how to handle the various uncertainties they face. This is an important conclusion because (1) it may imply that fairness and justice play a more important role in processes of uncertainty reduction than other social motives and (2) it implies that the origins of social justice are far more cognitive than was assumed thus far. We elaborate on this in the next paragraphs.

\section{Fairness versus Other Social Motives}

With respect to the question of why fairness matters we have presented data that show that fairness judgments are more important to people when they are uncertain about important aspects of themselves or their social environments. But why should concern with fairness be a response to such a wide variety of uncertainties? And is fairness more important in processes of uncertainty management than are other social psychological processes that have been discussed in social psychology; processes such as social identity and compensatory conviction (cf. Hogg \& Mullin, 1999; McGregor et al., 2001)?

One line of argument that supports the contention that fairness is a rather fundamental response to uncertainty is found in the widespread use of fairness by dyads, groups, and societies as they try to deal with social conflict and the uncertainty that attends it. Mikula and Wenzel (2000) argue convincingly that conflicting parties frequently use fairness and justice arguments in their disputes to strengthen and support their case. Fairness and justice principles are widely used as arguments to legitimize one's own actions and claims (Mikula, 1984; Reis, 1984), and descriptions of unfairness and injustice are used to discredit the opponent's position. 
Referring to fairness and justice when justifying actions and decisions emphasizes the individual's impartiality and transfers the responsibility for the action from the individual to the impersonal authority of norms of fairness and justice. Using appeals to fairness and justice when making a claim imbues the claim with greater legitimacy than referring to personal preferences or desires. Saying that one deserves, or is entitled to, something is more than saying that one wants it (Mikula \& Wenzel, 2000). Furthermore, labeling an action or decision as unfair and unjust simultaneously stresses the objectionable character of what happened and strengthens requests for a change or a compensation. This suggests that fairness is a persuasive force, arguably more persuasive than appeals to social identity (cf. Hogg \& Mullin, 1999), compensatory conviction (cf. McGregor et al., 2001), and individual differences in uncertainty orientation (cf. Sorrentino et al., in press).

Furthermore, there is evidence that fairness is a social organizing principle that may well be "built into the brain." That is, research by De Waal (1996) and others (e.g., Wright, 1994) shows that humans and other social mammals seem to share a concern for morality and justice: Not just social primates, but all species that live in groups, from marine mammals to dogs, respond to social rules and develop at least a crude sense of justice and fairness. Research findings by De Waal and his colleagues make a compelling case that natural selection has produced some highly successful species that survive through adhering to principles of fairness, justice, and morality. This suggests an evolutionary account of fairness, justice, and morality. Principles of fairness, justice, and morality may be crude or sophisticated, but the point is that the evolutionary success of various social species (including humans) depended and continues to depend on members following norms and values of fairness and related concepts. This suggests that fairness-and related concepts such as justice and morality - have a very special role in the life of humans and other social animals.

Related to this are research findings by Bobocel et al. (1998) that suggest that people's opposition to affirmative action can be rooted in a genuine concern with the violation of justice principles (see also Bobocel, Son Hing, Holmvall, \& Zanna, 2002; Lerner, 1977). Several theories of social justice have recognized that fairness, because it is a relatively straightforward and sensitive indicator of one's relationship with the external world, can give one confidence that whatever current uncertainty exists will not work against one's long-term well-being. Fair treatment implies that one is well positioned with respect to one's social environment (Lind \& Tyler, 1988; Lind, 1992, 1995, 2001), and there is evidence that this generalizes to enhanced self-esteem (Koper et al., 1993). We suggest that fairness helps manage uncertainty because it gives people a feeling of general security with respect to their social milieu and indeed that this feeling of security may generalize beyond social contexts. In addition, psychological theorists concerned with social justice have pointed out that fairness carries a promise of predictability and controllability that also diminishes the long-term risk associated with current uncertainty 
(e.g., Adams, 1965; Lind \& Tyler, 1988; Thibaut \& Walker, 1975; Walster et al., 1978). If one's environment and the people in it are fair, then one can expect to be able to control one's destiny and transient uncertainties are less threatening than they might otherwise be.

Fairness is a powerful antidote for uncertainty because it saves people the time and effort of analyzing complex policy or legal outcomes and of worrying about whether the outcomes were optimal, or even favorable, to them (Lind, 2001). A general implication of much of the field of behavioral decision making is that individuals are cognitively lazy and will utilize heuristics (among which are fairness heuristics; e.g., Lind, 2001; Messick, 1993) in order to judge a situation and simplify a decision task. The findings reviewed here suggest that, in addition to conserving cognitive resources, perceived fairness also substitutes for basic lack of subject matter knowledge (See, 2000; Van den Bos, Wilke, \& Lind, 1998). In terms used by Kelley and Thibaut (1978) in their interdependence theory, fairness judgments are the basis of a powerful transformation of objective outcomes and process, which enables people to decide whether to accept a given procedure or outcome not only on the basis of whether they can expect maximum benefit but instead on the basis of whether they view the social unit within which the authoritative decision is made as fair. In this sense, using fairness to manage uncertainty functions almost by definition. If the person believes that fair treatment will result in good, decent consequences, then almost any uncertainty can be ignored because the fair treatment implies that in the long run one can be certain of a good resolution of the uncertain issues. Of course, other social motives are important as well, but we think it is safe to conclude here that all this suggests that fairness and justice serve crucial and key roles in human life.

There are some interesting questions prompted by this view of the relationship between fairness and uncertainty, questions that might be fruitfully examined in future research. For example, one might ask whether fairness is useful in managing uncertainty because it eliminates uncertainty or because it makes uncertainty more tolerable. The long-term self-interest interpretation of the role of fairness suggests that feeling that one is treated fairly might make one confident of good outcomes in the long run, but there are interesting examples that suggest that fair treatment might render uncertainty not only nonaversive but even a positive experience. Consider, for example, the role of fairness in gambling, which we mentioned briefly earlier in the chapter. For many, a fair gamble is exciting precisely because of the combination of fairness and uncertainty. That there are credible arguments on both sides of this question makes it all the more intriguing.

\section{The Cognitive Origins of Social Justice Concerns}

An important implication of the research findings reviewed here is that they suggest that the origins of social justice concerns are far more cognitive than 
was previously assumed. For example, the studies reviewed above indicate that information uncertainty (e.g., Van den Bos, Wilke, \& Lind, 1998) or even subtle reminders of uncertainty (e.g., Van den Bos, 2001a) are sufficient to make fairness an important concern for people. Other aspects of social justice are important, of course, ${ }^{7}$ but we advance the hypothesis here that this is because of those aspects' relationship with uncertainty. For example, affect probably has an important role in the psychology of fairness judgments, but we propose here that this is because affect helps people to form judgments under conditions of uncertainty (cf. Forgas, 1995; Schwarz \& Clore, 1983). Similarly, relational aspects and group identification are demonstrably important to understand the social psychology of fairness judgments (e.g., Lind \& Tyler, 1988; Tyler \& Lind, 1992), but this is, we argue, because of their link with uncertainty (in this case uncertainty about standing in the group). Previous justice theories have focused on fairness as an organizing principle for group life, but they have ignored that the reason that such an organizing principle is needed is that social life is rife with uncertainty. Uncertainty describes and explains in a more direct and parsimonious way the social psychology of fairness judgments.

This hypothesis explains how fairness judgments, which social psychologists tend to think of as purely social beliefs, can be generalized to nonsocial aspects of life. If we think of fairness as an indicator of good positioning and predictability in our social environment, it is a short step to apply the concept to nonsocial events and processes. Thus, people tend to look for "fairness" in such things as a good return on their labor, even when the labor is done in an individual, nonsocial context and the return is not payment but a successful product. For example, it is "unfair" somehow when a computer failure deprives one of one's work product. Similarly, people sometimes see it as unfair when the weather on their vacation is bad (after all, they worked hard all year, so they deserve a sunny vacation!). ${ }^{8}$ The theory predicts that nonsocial fairness judgments should show the same dynamic-not necessarily of the same strength, but yielding qualitatively the same effects-as social fairness judgments: Nonsocial fairness judgments should become more important, receive more attention, and be moved to closure more rapidly under conditions of uncertainty as opposed to certainty. Our model yields research predictions that emphasize the importance of thinking about both social and nonsocial fairness judgments as truly subjective judgments; subjective judgments that are driven by uncertainty concerns. To be sure, we have a great deal yet to learn about nonsocial fairness judgments, but we predict here that they do not function much differently than social fairness judgments.

\footnotetext{
${ }^{7}$ Therefore, we are advancing a social-cognitive model-not just a cognitive model-here, encompassing not only cognitive aspects of the psychology of faimess judgments, but other aspects, such as group aspects (e.g., Lind \& Tyler, 1988), relational aspects (e.g.. Tyler \& Lind, 1992), and affect aspects (e.g., Tanaka \& Takimoto, 1997), as well.

${ }^{8}$ We have been informed, by the way, that one of our justice colleagues strongly shows this effect.
} 
Although fairness judgments are subjective judgments they are quite real to the person holding the judgment. In fact, we have argued repeatedly throughout this chapter that there is good evidence to argue that people genuinely are concerned with fairness principles and honestly are trying to arrive at reasonable judgments about what is fair or unfair (e.g., Bobocel et al., 1998; De Waal, 1996; Lerner, 1977). However, we suggest here that the cognitive origins of fairness judgments make people genuinely believe in their fairness judgments without them realizing that these judgments are really in the eye of the beholder and without them having good insights into the biases in their construction of these judgments (cf. Nisbett \& Ross, 1980). Future research might profitably explore this subtle paradox of fairness judgments: the fact that they are at once subjective and yet treated as though they had objective reality. This may reveal, among other things, conditions under which people treat "fairness" as virtually synonymous with "satisfaction" and "goodness" and conditions under which these constructs have very different connotations to people and hence have very different effects on their cognitions, feelings, judgments, and behaviors (cf. Van den Bos, Wilke, Lind, \& Vermunt, 1998).

Our model also raises the possibility of other categories of cognition that might serve the same function as fairness judgments and that might be similarly affected by uncertainty. Our uncertainty management model leads us to predict that cognitions that give one an indication of either positioning or controllability would receive more attention under uncertainty. Two possibilities are judgments about social identity (cf. Hogg \& Mullin, 1999) and judgments about self-efficacy (cf. Bandura, 1986). Social identity positions one in a social category and gives some certainty about what sort of person one is; self-efficacy gives reassurance that however the uncertainty in question works out, one can probably deal with it. Our model yields the testable prediction that these cognitions will show the same enhanced uncertainty-moderated attention effects that fairness judgments do. Interestingly, research by Hogg and colleagues does in fact suggest that uncertainty reduction is a central goal of group membership and is a major force behind the need for perceptions of group entativity and feelings of belongingness (Hogg, in press; Hogg \& Abrams, 1993; Hogg \& Mullin, 1999). As we noted above, however, we think fairness judgments are probably more useful and convincing (cf. Mikula \& Wenzel, 2000) in processes of uncertainty management than group membership or self-efficacy.

The findings we have described here show that the origins of social justice are far more cognitive than has been assumed in the past. If our analysis is correct, then one of the main reasons that people care about fairness is because it gives them a way to manage uncertainty, a quintessentially cognitive motive. The change in emphasis (compared to older, more group-oriented theories of fairness) we propose with our social-cognitive model calls for a new motivational emphasis in the social psychology of fairness: an epistemic motivation to reduce subjective uncertainty. 


\section{B. HOW PEOPLE FORM FAIRNESS JUDGMENTS IN AN UNCERTAIN WORLD}

With regard to the question of how fairness judgments are formed, the findings reviewed here show that in situations where people are uncertain about their fairness judgments they tend to rely on fairness substitution heuristics. Furthermore, the findings show that as people form fairness judgments they overcome uncertainty in this process by seizing on early indicators that things are fair or unfair.

It is interesting to speculate about whether substitution and anchoring processes exist within other cognitions that help people deal with uncertainty. It is intriguing to speculate that social identity and self-efficacy information might show effects similar to those that we have seen in fairness judgments. Might not social identity information be especially potent immediately after uncertainty is confronted and less potent later? Might there not be substitutability among various dimensions of social identity or self-efficacy, along the same lines as the fairness substitutability effects we have seen in a number of experiments? It might even be the case that substitution works across uncertainty-resolving cognitions. Might it be the case, for example, that-especially when the context is uncertain-indications of fair treatment are especially likely to enhance social identity or self-efficacy judgments? Investigating these research propositions may contribute to integration of social psychological research domains.

The findings discussed here indicate that cognitive processes-such as substitution and anchoring processes-play a major role in the construction of fairness judgments. Previous justice research tended to focus on the social aspects of fairness judgments and have for this reason, we would contend, missed some interesting fairness phenomena. Clearly our contention is that the findings presented here show that the construction of fairness judgments can best be understood by means of a social-cognitive model. We have sought to present such a model here, and we hope that this model will stimulate future research to explore both the socially situated and cognitive aspects of fairness judgments and more theoretical work on the social and cognitive sides of fairness.

Our model suggests that uncertainty plays a far more important role in the psychology of fairness judgments than previous theories have assumed. That is, previous justice theories tended to predict that particular aspects of social lifesuch as trust, neutrality, standing, and social identity (Lind \& Tyler, 1988; Tyler \& Lind, 1992) - always led to positive fairness judgments. Our model suggests, however, that people can be, and perhaps frequently are, uncertain about these aspects and that quite different effects are to be expected depending on whether the person forming the fairness judgment feels certain or uncertain (see, e.g., Van den Bos, Wilke, \& Lind, 1998). This reveals important boundary conditions under which the effects predicted by previous theories may not hold. 
In a way, our model goes a step beyond Festinger's (1954) social comparison theory. Festinger proposed that when objective information is not available people start using information that they glean from comparisons to the beliefs, actions, or outcomes of others. We go further by suggesting that when objective and social comparison information is absent- that is, when information uncertainty is present-people start to rely on other, more subjective information (specifically information about how fairly they have been treated) to deal with their lack of knowledge (e.g., Van den Bos, Lind, et al., 1997). Thus, we argue that the use of fairness as an uncertainty management technique may occur not only when people are uncertain about objective information but also when they are uncertain about social comparison information. This in turn suggests that uncertainty plays a more fundamental role in the fairness judgment process than has been contemplated by previous social comparison-based theories of justice (for an overview, see Messick, 1993), which have seen social comparison as a fairness judgment process rather than fairness as a solution to weak social comparisons. This brings us to the implications of our work for previous theories of fairness judgments. We discuss these implications in the next section.

\section{RECASTING THE SOCIAL PSYCHOLOGY OF JUSTICE}

In this section we argue that, interestingly, a number of previous justice theories implicitly have assumed uncertainty to be an important construct in the processes these theories were proposing. With this in mind, it may be time to start recasting these frameworks to make explicit the important, but hitherto only implicit, role that uncertainty has had in the theories' explanations of the social psychology of fairness judgments.

Equity theory (e.g., Adams, 1965; Walster et al., 1973, 1978), relative deprivation theory (e.g., Crosby, 1976; Stouffer et al., 1949), and referent cognitions theory (e.g., Cropanzano \& Folger, 1989, 1991; Folger, 1986, 1987; Van den Bos \& Van Prooijen, 2001) differ in a number of ways but all emphasize that fairness judgments are made relative to referents, such as social comparison others. These theories all incorporate, in one way or another, Festinger's (1954) line of reasoning that frequently people need social comparisons because they have no objective information. We argue that these theories in fact all implicitly assume that people are uncertain whether the events they have experienced are fair or unfair and hence turn to referential information, such as social comparisons, in the fairness judgment process. Thus, we argue here that all of these theories make use of some uncertainty reduction process in the way they explain the how of fairness judgments. These theories also make implicit use of the concept of uncertainty reduction in their accounts of the why of fairness judgments. Equity theory can be 
seen as a special theory of uncertainty reduction in that equity gives people a way to resolve uncertainty about the meaning of outcomes (cf. Adams, 1965).

We argue that the Thibaut and Walker (1975) instrumental model, ${ }^{9}$ Lind and Tyler (1988) group-value model, and Tyler and Lind (1992) relational model all implicitly assume fairness serves to reduce uncertainty. The Thibaut and Walker model suggests that people want to have control over the decision or over the processes that lead to a decision so that they can make sure that the ultimate outcome is fair. Although Thibaut and Walker do not directly or indirectly address feelings of uncertainty, the idea that people do not willingly surrender control over important social processes, which is one of the central tenets of their model, is certainly consistent with our position that people define and use fairness in ways that help them deal with uncertain situations.

We argue here that the instrumental model is more restricted to outcome considerations of fairness judgments than our model is. Our model definitely incorporates outcome aspects but also encompasses other aspects. Furthermore, our concept of uncertainty is broader than Thibaut and Walker's conceptualization of control. For example, our model suggests that less obvious things than control-such as subtle reminders of uncertainty (cf. Van den Bos, 2001a)-are sufficient to stimulate fairness concerns. Our work definitely has been inspired by Thibaut and Walker's work (in fact, one of us did his Ph.D. thesis with these founders of procedural justice), but also goes beyond where they stopped.

The group-value and relational models see fairness as reducing uncertainty about one's position and inclusion in groups (Lind \& Tyler, 1988; Tyler \& Lind, 1992). Thus these two models are congruent with, but more limited than, our present theory. The use of fairness to reduce uncertainty about social standing can be seen as a special case of the idea that fairness is used to reduce uncertainty across a wider variety of questions, including but not limited to questions of social standing (cf. Van den Bos et al., 1999). The group-value and relational models, as well as the Thibaut and Walker (1975) instrumental model, have been very important for the social psychology of fairness, but because we incorporate in one theory the social, cognitive, and subjective aspects of fairness judgments, we think our model is broader than any of these previous models.

Work by Lerner and colleagues (e.g., Hafer, 2000; Lerner, 1980; Lerner \& Miller, 1978) assumes that people use just world beliefs to resolve cognitive uncertainty in person perception. One could argue that a ubiquitous belief in a just world provides a psychological justification for using fairness to reduce uncertainty. In particular, holding strongly to the belief that the world is just and derogating victims in service of this belief can reduce uncertainty about why individuals get

\footnotetext{
${ }^{9}$ We emphasize here that we think an important aspect of the Thibaut and Walker (1975) model was the focus on whether people received fair outcomes and not so much on how favorable outcomes were to people. We are therefore referring to these authors' theory as the "instrumental model," and we think it is wrong to label this the "self-interest model," as is often done in the current literature.
} 
bad outcomes. The belief in a just world may lead people to not see injustice done to others. A related phenomenon is seen in the fact that people who themselves are disadvantaged often fail to see their disadvantages as an instance of injustice (e.g., Crosby, 1982, 1984; Major, 1994; Taylor, Wright, \& Porter, 1994). Thus our current analysis is congruent with the Lerner just world hypothesis. There is, if one considers the Lerner hypothesis in conjunction with our current analysis, an interesting prediction: It may well be the case that people who feel uncertain have a stronger tendency to legitimize injustice and hence have more difficulty acknowledging that the way they or others were treated was unjust. We think that the model we have presented here has the potential to inspire researchers who thus far have held different theoretical perspectives to try to integrate their perspectives with the uncertainty management model. This will broaden both our model and other fairness theories.

Our analysis suggests that uncertain individuals will make more use of the equality heuristic (Messick, 1993; Messick \& Schell, 1992). Messick argues that equality is often a useful heuristic that is used to facilitate decision making in situations involving the allocation of good and bad outcomes. There are a number of different reasons for this. These reasons include, first, that equality is a simple rule to apply. An allocator typically only needs to know the number of individuals to share whatever is being divided. Second, equality is a rule that does not require the identity, qualities, or contributions of the parties involved in the allocation process. Third, even in situations in which all involved agree that equality constitutes an inappropriate allocation, it can nevertheless be a very useful anchor from which adjustments can be made. In the context of our analysis here, we argue that the equality heuristic is used to reduce an allocator's uncertainty about whether the outcomes that are to be allocated are fair or unfair.

Fairness heuristic theory - an account of social fairness judgments that shares many elements with our current, more general, theory-also posits that people often process fairness-related information by relying on heuristics (for an overview of different heuristics people use, see Van den Bos et al., 2001; for overviews of fairness heuristic theory, see, e.g., Lind, 2001; Van den Bos, 2001b). Fairness heuristic theory can, to a large extent, be viewed as special case of our current theory. In fact, many of the studies reviewed in the previous sections originated from the fairness heuristic framework. Fairness heuristic theory links fairness judgment processes to uncertainty, but its main focus has been on heuristic processing of fairness information, especially in social contexts. What we have tried to do in the current chapter is to argue more explicitly than we have in our previous writings (e.g., Lind, 2001, Van den Bos, 2001b; Van den Bos et al., 2001) that uncertainty is a crucial assumption in the processes that fairness heuristic theory has stipulated. In many ways, what we are attempting in this chapter is to expand fairness heuristic theory to be a theory of uncertainty management. We think this is important because the psychology of fairness and justice encompasses more than just heuristic 
processes. Our aim in the current chapter, therefore, was to build a broader theory of fairness judgments.

Most studies that were reviewed here were driven by a motivation to try to integrate procedural and distributive justice orientations. In the past, procedural justice researchers focused on the finding that perceived procedural fairness often affects people's reactions more strongly than outcome fairness perceptions (see, e.g., Lind \& Tyler, 1988, p. 1), and this led them to focus on only one type of fairness-relevant information and only one dimension of fairness judgment: procedures and procedural fairness. Distributive justice researchers, on the other hand, also tended to focus on only one type of fairness-relevant information and only one dimension of fairness judgment: outcomes and distributive fairness (e.g., Lerner \& Whitehead, 1980; Rutte \& Messick, 1995). Thus, both procedural and distributive justice research have tended to focus on only one aspect of the faimess judgment process, at the expense of other fairness dimensions. However, as several authors have pointed out, our field would certainly be more comprehensible if procedural and distributive justice orientations could be integrated (e.g., Brockner \& Wiesenfeld, 1996; Cropanzano \& Folger, 1991; Greenberg, 1990).

We believe that our research has contributed to an integration of procedural and distributive justice orientations. Our work has shown, for example, that how people form procedural and distributive fairness judgments depends on both the procedural information and the outcome information they are reacting to (Van den Bos, 1999; Van den Bos, Lind, et al., 1997; Van den Bos, Wilke, Lind, \& Vermunt, 1998) and the order in which they receive information about procedures and outcomes (Van den Bos, Vermunt, \& Wilke, 1997). In fact, we think integration of the two dimensions of the psychology of justice has been so successful that it is now time to start developing general theories about fairness judgments, encompassing both procedural and distributive fairness judgments and both procedural and distributive justice considerations. We therefore have proposed such a general theory here. We view procedural and distributive justice not as wholly different constructs, but rather as two aspects of overarching general fairness beliefs. Indeed, the fact that we offer a theory of all types of fairness judgments and the fact that we address explicitly the role of uncertainty in motivating and shaping fairness judgments are what distinguish our theory from those that have come before.

Now that we have developed a general theory of fairness judgments we think it is time to start investigating the specific psychological processes we have proposed here. This may yield greater insights into how precisely fairness contributes to processes of uncertainty management. In the current chapter we have used a broad conception of uncertainty. This was useful for developing our theory of uncertainty management, we think, because it allowed us to draw on various research traditions, including theories of uncertainty resolution, human judgment under uncertainty, and anchoring effects in uncertain situations, in ways that we found useful for the thinking about the psychology of fairness judgments. However, we can see value in 
future research that focuses on differences between different forms of uncertainty and differences between various research traditions related to uncertainty and fairness. After all, different conceptions of uncertainty may yield different fairness processes. For example, uncertainties that are threatening to people's selves (we call this "hot uncertainty") may lead them to start relying on whatever information is available, regardless of whether this information is relevant (cf. Tesser, 2000), whereas uncertainties that are not threatening to people's selves (we label this "cold uncertainty") may lead them to use only information which is relevant to the uncertainty at hand and to be less affected by irrelevant information (cf. Van den Bos \& Lind, 2001).

In this section, we have speculated about the implications our uncertainty management model may have for other theories about social justice. In the next section, we discuss the implications of our model for the social psychology of managing uncertainty.

\section{THE SOCIAL PSYCHOLOGY OF MANAGING UNCERTAINTY}

The previous sections suggest that uncertainty and how people manage uncertainty are important issues in the social psychology of fairness judgments and that fairness judgments are subjective constructions that are used in processes of uncertainty management. Here we discuss the implications of our work on fairness judgments for some of the literatures in social psychology that address uncertainty and how people deal with uncertainties in social life.

As noted previously in this chapter, uncertainty plays an important role in human life. As we have also noted, this is not to say that people want to reduce uncertainty all the time. But even when uncertainty is sought, it is still managed. In addition, diverse research traditions within social psychology have demonstrated convincingly that there are clearly situations in which the reduction of uncertainty is important in people's lives. These include the social psychological literatures on human judgment under uncertainty (e.g., Kahneman et al., 1982), human inference (e.g., Nisbett \& Ross, 1980), social dilemmas (e.g., Van Dijk et al., 1997), individual differences in uncertainty orientation (e.g., Sorrentino et al., 1984, in press), self-categorization aspects of uncertainty (e.g., Hogg, in press; Hogg \& Abrams, 1993; Hogg \& Mullin, 1999), and uncertainty as a general psychological concept (e.g., Garner, 1962; Kagan, 1972).

Hogg (in press) has noted that epistemic motives related to uncertainty have a high profile in social psychology. For example, epistemic motives are important in research on the self (e.g., Banaji \& Prentice, 1994; Sedikides \& Strube, 1995, 1997; Swann \& Schroeder, 1995) and in Festinger's (1954) work on social comparison. Communication researchers believe that people communicate to reduce uncertainty and that effective communication itself requires a substantial level of interpersonal 
certainty (e.g., Berger, 1987; Berger \& Bradac, 1982; Gudykunst \& Shapiro, 1996; Gudykunst, Yang, \& Nishida, 1985). Many social psychologists study individual differences in uncertainty-related motives. These include Adorno, FrenkelBrunswik, Levinson, and Sanford's (1950) description of the authoritarian personality; Rokeach's $(1948,1960)$ notion of a dogmatic or close-minded personality; Sorrentino's work on uncertainty orientation (e.g., Brouwers \& Sorrentino, 1993; King \& Sorrentino, 1988; Roney \& Sorrentino, 1995; Sorrentino, Bobocel, Gitta, Olson, \& Hewitt, 1988; Sorrentino, Holmes, Hanna, \& Sharp, 1995; Sorrentino \& Short, 1986); and research by Kruglanski and others on the needs for structure and closure and the fear of invalidity (e.g., Kruglanski, 1989; Kruglanski \& Webster, 1996; Thompson \& Zanna, 1995).

Uncertainty and how people manage uncertainty in their lives play a central role in theories focusing on interpersonal relations, individual differences, and groups (Hogg, in press; Sorrentino et al., 1984, in press). In the interpersonal relations domain, Berger and Calabrese (1975) argue that the entire goal of interpersonal communication is to reduce uncertainty about the message being conveyed and about the relations between communicators. Holmes and Rempel (1989) perceive uncertainty reduction as the central goal in establishing trust between partners. Sorrentino and associates have explored the role of uncertainty orientation as an individual difference variable (e.g., Sorrentino et al., 1984, in press). Uncertaintyoriented people seek out uncertainty. Especially relevant for the current purposes are certainty-oriented persons, who tend to look for certainty in their lives. We propose here that certainty-oriented individuals will show more strongly the fairness effects reviewed in this chapter. Sorrentino et al. (in press) argue convincingly that research has focused on uncertainty-oriented individuals to the relative, or indeed absolute, neglect of certainty-oriented persons, and they make a plea that this must change. Work by Hogg and others suggests that an important way to reduce feelings of uncertainty is through self-categorization and that uncertainty reduction is a core motive for social identity processes (Hogg, in press; Hogg \& Abrams, 1993; Hogg \& Mullin, 1999). This line of work suggests that uncertainty reduction is a central goal of group membership and is a major force behind the need for perceptions of group entativity and feelings of belongingness.

System justification theory (Jost, 1995; Jost \& Banaji, 1994) suggests that uncertainty is aversive and that, to avoid uncertainty, people try to justify rather than challenge an existing status quo. Jost and his colleagues argue that this idea is consistent with research in a number of areas such as the failure to perceive injustice (Crosby, 1982), the just world hypothesis (Lerner, 1980), institutional loyalty (Tyler, 1990), stereotypic rationalization (Hoffman \& Hurst, 1989), hierarchy enhancement (Pratto, Sidanius, Stallworth, \& Malle, 1994), false consciousness (Jost, 1995), and legitimacy of inequality (Major, 1994). We think it is fair to say that our model also has much to say about precisely why people tend to justify the existing status quo (and about other fairness-related ways of dealing with uncertainty) and 
in this we see a convergence of our concerns with those of Jost and his colleagues. System justification theory is important to our current discussion also because it brings us back to fairness judgments- the primary focus of attention in this chapter.

Turning to the relationship between our fairness perspective on uncertainty management and the group and individual differences perspectives (Hogg \& Mullin, 1999; Sorrentino et al., in press), we propose that, for the reasons described previously (see, e.g., Mikula \& Wenzel, 2000), fairness judgments are more powerful and convincing in processes of uncertainty management than are group membership or individual differences in uncertainty orientation. Furthermore, interestingly, our fairness research represents a middle position between the group orientation of Hogg and colleagues (e.g., Hogg \& Mullin, 1999) and the individual orientation of Sorrentino and associates (e.g., Sorrentino et al., in press). That is, our model concentrates on the role of interpersonal uncertainty, but also tries to incorporate both group and individual aspects. Perhaps then our model will contribute to an integration of previous uncertainty reduction models. We do not intend to propose here that our work encompasses all previous models of resolving uncertainty, but we hope to have shown in this chapter that uncertainty management by means of fairness judgments deserves special attention in the social psychology of managing uncertainty. This brings us to our conclusions.

\section{Conclusions}

In this chapter we argued that why and how fairness judgments are formed are tied profoundly to processes of uncertainty management. We reviewed research findings that showed that fairness is important for people because they use fairness judgments in processes of uncertainty management. We reasoned that fairness and justice may play a more important role in human life than other social motives and that the origins of social justice are far more cognitive than was assumed thus far. Furthermore, we argued that when forming fairness judgments people are busy resolving uncertainties they encounter in the fairness judgment process itself. Findings were discussed that indicate that as people form fairness judgments they overcome uncertainty in this process by using information on one form of justice to assess others and by seizing on early indicators that things are fair or unfair.

We discussed the implications of the research findings we have reviewed with respect to why and how people are in need for fairness judgments in an uncertain world. Most of these implications followed directly from data that were discussed here. Some implications followed logically from the research findings but still require empirical validation. Thus, we want to emphasize explicitly that some of our statements have to be interpreted as research propositions for future studies. 
Nevertheless, we think there are some good reasons to explain and describe the psychology of fairness judgments by explicitly referring to processes of uncertainty management. We therefore proposed a model of uncertainty management by means of fairness judgments. Furthermore, we presented questions for future research and suggestions for how these questions may be answered. We discussed the implications of our position for the social psychology of justice and fairness and discussed future directions the field may want to take. We also discussed the relevance of our model for the social psychology of uncertainty management in general.

We want to make a point here on the methodology used in most of the studies reviewed. In this chapter we argued that because much of the existing empirical literature on the psychology of fairness has employed correlational research methods within real-life situations, social psychologists know quite a lot of the effects fairness judgments can have on people in a multitude of situations. However, this knowledge may have been achieved at the expense of thorough insights into the two most fundamental issues of social justice: why do people care about fairness and how are fairness judgments formed? We hope to have shown here that the fundamentals of the why and how of social justice are probably better investigated by means of research methods that are best equipped to study fundamental issues: laboratory experiments. In the current chapter, we tried to illustrate that it is important to do fundamental research by means of laboratory methodologies and that laboratory experiments serve an essential, crucial role in the study of social fairness.

In this chapter we have discussed a new perspective on the social psychology of fairness, a perspective that leads to a number of novel insights and predictions. First and foremost, of course, is the insight that fairness matters to people to a greater or lesser extent as a function of their feelings of uncertainty. As we noted above, we believe that the search for fairness information is a general response to uncertainty. Our analysis suggests that many of the standard fairness phenomena will be stronger in the face of uncertainty, and similarly it predicts that the new fairness effects we have described in this chapter-effects like the substitutability of one fairness dimension for another or the primacy effects in fairness judgmentswill be enhanced by uncertainty. Our analysis leads to testable predictions that receiving fair treatment should reduce the anxiety that typically accompanies uncertainty or should lead people to better tolerate the uncertainty.

There are other insights and predictions that flow from the model we have advanced in this chapter. Among the most novel are our suggestion that people often apply fairness considerations to nonsocial events and our prediction that different processes involved in uncertainty management-dimensions such as fairness, social identity, or self-efficacy - might show the same sort of mutual substitutability effects we have seen occur across different justice dimensions. If we are right that attention to fairness judgments is perhaps the most common response to 
uncertainty, across both social and nonsocial contexts, then the existing research literature on the social psychology of justice and fairness has much wider applicability than has been thought. If we are correct about cross-process substitutability, involving fairness and other uncertainty management processes, then processes involving fairness, social identity, and self-oriented judgments are far more intimately connected than one would have thought from existing theory on any of these processes. These implications are now open to empirical tests, and if the theory fares well when these tests are conducted, we may end up with a remarkably different understanding of the role of fairness in social psychology. This would imply that managing uncertainty by means of fairness judgments is perhaps even more important than we proposed it to be in this chapter.

\section{Acknowledgments}

Preparation of this chapter was supported by National Science Foundation Grants SBR-96-96244 and SBR-99-06771 and a fellowship of the Royal Netherlands Academy of Arts and Sciences awarded to Kees van den Bos. We thank Ramona Bobocel, Joel Brockner, Catrin Finkenauer, Ian McGregor, Linda Skitka, Asteria Straathof, Jan-Willem van Prooijen, Henk Wilke, Jan Fekke Ybema, and Mark Zanna for their helpful comments on previous versions. We are grateful to Jerald Greenberg for his help in understanding the organizational literature on change and fairness.

\section{References}

Adams, J. S. (1965). Inequity in social exchange. In L. Berkowitz (Ed.), Advances in experimental social psychology (Vol. 2, pp. 267-299). New York: Academic Press.

Adorno, T. W., Frenkel-Brunswik, E., Levinson, D. J., \& Sanford, R. N. (1950). The authoritarian personality. New York: Harper.

Alexander, S., \& Ruderman, M. (1987). The role of procedural and distributive justice in organizational behavior. Social Justice Research, 1, 117-198.

Ambrose, M. L., \& Kulik, C. T. (2001). How do I know that's fair? A categorization approach to fairness judgments. In S. W. Gilliland, D. D. Steiner, \& D. P. Skarlicki (Eds.), Theoretical and cultural perspectives on organizational justice (pp. 35-62). Greenwich, CT: Information Age.

Austin, W., McGinn, N. C., \& Susmilch, C. (1980), Internal standards revisited: Effects of social comparisons and expectancies on judgments of faimess and satisfaction. Joumal of Experimental Social Psychology, 16, 426-441.

Banaji, M. R., \& Prentice, D. J. (1994). The self in social contexts. Annual Review of Psychology, 45, 297-332.

Bandura, A. (1986). Social foundations for thought and action: A sacial cognitive theory. Englewood Cliffs, NJ: Prentice Hall.

Berger, C. R. (1987). Communicating under uncertainty, In M, E. Roloff \& G. R. Miller (Eds.). Interpersonal processes: New directions in communication research (pp, 39-62). Newbury Park, CA: Sage. 
Berger, C. R., \& Bradac, J. J. (1982). Language and social knowledge: Uncertainty in interpersonal relations. London: Edward Amold.

Berger, C. R., \& Calabrese, R. J. (1975). Some explorations in initial interaction and beyond: Toward a developmental theory of interpersonal communication. Human Communication Research, 1 , 99-112.

Berkowitz, L., \& Walster, E. (Eds.). (1976). Advances in experimental social psychology: Volume 9. Equity theon-Toward a general theory of social interaction. New York: Academic Press.

Blau, P. M. (1964). Exchange and power in social life. New York: Wiley.

Bobocel, D. R., Agar, S. E., Meyer, J. P., \& Irving, P. G. (1998). Managerial accounts and fairness perceptions in conflict resolution: Differentiating the effects of minimizing responsibility and providing justification. Basic and Applied Social Psychology, 20, 133-143.

Bobocel, D. R., Son Hing, L. S., Davey, L. M., Stanley, D. J., \& Zanna, M. P. (1998). Justice-based opposition to social policies: Is it genuine? Journal of Personality and Social Psychology, 75, 653-669.

Bobocel, D. R., Son Hing, L. S., Holmvall, C. M., \& Zanna, M. P. (2002). Policies to redress social injustice: Is the concern for justice a cause both of support and of opposition? In M. Ross \& D. Miller (Eds.), The justice motive in everyday life (pp. 204-225). New York: Cambridge Univ. Press.

Boles, T. L., \& Messick, D. M. (1990). Accepting unfaimess: Temporal influence on choice. In K. Borcherding, O. I. Larichev, \& D. M. Messick (Eds.), Contemporary issues in decision making (pp. 375-389). Amsterdam: Elsevier.

Brockner, J., DeWitt, R. L., Grover, S., \& Reed, T. (1990). When it is especially important to explain why: Factors affecting the relationship between managers' explanations of a layoff and survivors' reactions to the layoff. Journal of Experimental Social Psychology, 26, 389-407.

Brockner, J., \& Greenberg, J. (1990). The impact of layoffs on survivors: An organizational justice perspective. In J. S. Carroll (Ed.), Applied social psychology and organizational settings (pp. 45-75). Hillsdale, NJ: Erlbaum.

Brockner, J., Grover, S., Reed, T., DeWitt, R. L., \& O'Malley, M. (1987). Survivors reactions to layoffs: We get by with a little help from our friends. Administrative Science Quarterly, 32, 526-541.

Brockner, J., Heuer, L., Siegel, P. A., Wiesenfeld, B., Martin, C., Grover, S., Reed, T., \& Bjorgvinsson, $\mathrm{S}$. (1998). The moderating effect of self-esteem in reaction to voice: Converging evidence from five studies. Joumal of Personality and Social Psychology, 75, 394-407.

Brockner, J., Konovsky, M., Cooper-Schneider, R., Folger, R., Martin, C., \& Bies, R. J. (1994). Interactive effects of procedural justice and outcome negativity on victims and survivors of job loss. Academy of Management Journal, 37, 397-409.

Brockner, J., \& Wiesenfeld, B. M. (1996). An integrative framework for explaining reactions to decisions: Interactive effects of outcomes and procedures. Psychological Bulletin, 120, 189-208.

Brouwers, M. C., \& Sorrentino, R. M. (1993). Uncertainty orientation and protection motivation theory: The role of individual differences in health compliance. Joumal of Personality and Social Psychology, 65, 102-112.

Cobb, A. T., Wooten, K. C., \& Folger, R. (1995). Justice in the making: Toward understanding the theory and practice of injustice in organizational change and development. In W. A. Pasmore \& R. W. Woodman (Eds.), Research in organizational change and development (Vol. 8, pp. 243295), Greenwich, CT: JAI Press.

Cohen, R. L. (1986). Justice: Views from the social sciences. New York: Plenum.

Cropanzano, R., \& Folger, R. (1989). Referent cognitions and task decision autonomy: Beyond equity theory. Journal of Applied Psychology, 74, 293-299.

Cropanzano, R., \& Folger, R. (1991). Procedural justice and worker motivation. In R. M. Steers \& L. W. Porter (Eds.), Motivation and work behavior (Vol. 5, pp. 131-143). New York: McGraw-Hill. 
Cropanzano, R., \& Greenberg, J. (1997). Progress in organizational justice: Tunneling through the maze. In Cooper C. L. \& I. T. Robertson (Eds.), Intemational neview of industrial and organizational psychology (pp. 317-372). New York: Wiley.

Crosby. F. (1976). A model of egoistical relative deprivation. Psychological Review, 83, 85-112.

Crosby, F. (1982). Relative deprivation and working women. New York: Oxford Univ. Press.

Crosby, F. (1984). The denial of personal discrimination. American Behavioral Scientist, 27, 371-386.

Daly, J. P., \& Geyer, P. D. (1994). The role of fairness in implementing large-scale change: Employee evaluations of process and outcomes in seven facility relocations. Journal of Organizational Behavior, 15, 623-638.

Daly, J. P., \& Tripp, T. M. (1996). Is outcome fairness used to make procedural faimess judgments when procedural information is inaccessible? Social Justice Research, 9, 327-349.

Deutsch, M. (1975). Equity, equality, or need? What determines which value will be used as the basis of distributive justice? Journal of Social Issues, 31, 137-149.

Deutsch, M. (1985). Distributive justice: A sacial psychological perspective. New Haven, CT: Yale University Press.

De Vries, S., \& Wilke, H. A. M. (1991), Constrained egoism and resource management under uncertainty. In W. Liebrand, D. M. Messick, \& H. A. M. Wilke (Eds.), A social psychological approach to social dilemmas, Oxford, UK: Pergamon Press.

De Waal, F. (1996). Good natured: The origins of right and wrong in humans and other animals. Cambridge, MA: Harvard Univ. Press.

Eddy, E. R., Stone, D. L., \& Stone-Romero, E. F. (1999). The effects of information management policies on reactions to human resource information systems: An integration of privacy and procedural justice perspectives. Personnel Psychology, 52, 335-358.

Festinger, L. (1954). A theory of social comparison processes. Human Relations, 7, 117-140.

Fiske, S. T., \& Taylor, S. E. (1991). Social cognition (2nd ed.). New York: McGraw-Hill.

Folger, R. (1977). Distributive and procedural justice: Combined impact of "voice" and improvement of experienced inequity. Joumal of Personality and Social Psychology, 35, 108-119.

Folger, R. (1986). Rethinking equity theory: A referent cognitions model. In H. M. Bierhoff, R. L. Cohen, \& J. Greenberg (Eds.), Justice in social relations (pp. 145-162). New York: Plenum.

Folger, R. (1987). Reformulating the preconditions of resentment: A referent cognitions model. In J. C. Masters \& W. P. Smith (Eds.), Social comparison, social justice, and relative deprivation: Theoretical, empirical, and policy perspectives (pp. 183-215). Hillsdale, NJ: Erlbaum.

Folger, R., \& Cropanzano, R. (1998). Organizational justice and human resource management. Thousand Oaks, CA: Sage.

Folger, R., \& Konovsky, M. (1989). Effects of procedural and distributive justice on reactions to pay raise decisions. Academy of Management Journal, 32, 115-130.

Folger, R., Rosenfield, D., Grove, J., \& Corkran, L. (1979). Effects of "voice" and peer opinions on responses to inequity. Joumal of Personality and Social Psychology, 37, 2253-2261.

Forgas, J. P. (1995). Mood and judgment: The Affect Infusion Model (AIM). Psychological Bulletin, 117, 39-66.

Garner, W. R. (1962). Uncertainty and structure as psychological concepts. New York: Wiley.

Gilliland, S. W. (1994). Effects of procedural and distributive justice on reactions to a selection system. Joumal of Applied Psychology, 79, 691-701.

Greenberg, J. (1990). Organizational justice: Yesterday, today, and tomorrow, Journal of Management, $16,399-432$.

Greenberg, J. (1993). Stealing in the name of justice: Informational and interpersonal moderators of theft reactions to underpayment inequity. Organizational Behavior and Human Decision Processes, 54. $81-103$.

Greenberg, J. (1994). Using socially fair treatment to promote acceptance of a work site smoking ban. Journal of Applied Psychology, 79, 288-297. 
Greenberg, J. (1997). A social influence model of employee theft: Beyond the fraud triangle. In R. J. Lewicki, R. J. Bies, \& B. H. Sheppard (Eds.), Research on negotiation in organizations (Vol. 6, pp. 29-52). Greenwich, CT: JAI Press.

Greenberg, J., \& Lind, E. A. (2000). The pursuit of organizational justice: From conceptualization to implication to application. In C. L. Cooper \& E. A. Locke (Eds.), L/O psychology: What we know about theory and practice (pp. 72-105), Oxford, UK: Blackwell.

Greenberg, J., Pyszczynski, T., Solomon, S., Rosenblatt, A., Veeder, M., Kirkland, S., \& Lyon, D. (1990). Evidence for terror management theory II: The effects of mortality salience on reactions to those who threaten or bolster the cultural worldview. Journal of Personality and Social Psychology, $58,308-318$.

Greenberg, J., Solomon, S., \& Pyszczynski, T. (1997). Terror management theory of self-esteem and cultural worldviews: Empirical assessments and conceptual refinements. In M. P. Zanna (Ed.), Advances in experimental social psychology (Vol. 29, pp. 61-139). New York: Academic Press.

Gudykunst, W. B., \& Shapiro, R. B. (1996). Communication in everyday interpersonal and intergroup encounters. International Joumal of Intercultural Relations, 20, 19-46.

Gudykunst, W. B., Yang, S. M., \& Nishida, T. (1985). A cross-cultural test of uncertainty reduction theory: Comparisons of acquaintance, friend, and dating relationships in Japan, Korea, and the United States, Human Communication Research, 11, 407-455.

Hafer, C. L. (2000). Do innocent vietims threaten the belief in a just world? Evidence from a modified Stroop task. Journal of Personality and Social Psychology, 79, 165-173.

Heatherton, T. F., \& Polivy, J. (1991). Development and validation of a scale for measuring state self-esteem. Journal of Personality and Social Psychology, 60, 895-910.

Hoffman, C., \& Hurst, N. (1989). Gender stereotypes: Perception or rationalization? Journal of Per. sonality and Social Psychology, 58, 197-208.

Hofstede, G. (1980). Culture's consequences: International differences in work related values. Beverly Hills, CA: Sage.

Hogg, M. A. (in press). Self-categorization and subjective uncertainty resolution: Cognitive and motivational facets of social identity and group membership. In J. P. Forgas, K. D. Williams \& L. Wheeler (Eds.), The social mind: Cognitive and motivational aspects of interpersonal behavior. New York: Cambridge Univ. Press.

Hogg, M. A., \& Abrams, D. (1990). Social motivation, self-esteem and social identity. In D. Abrams \& M. A. Hogg (Eds.), Social identity theory: Constructive and critical advances (pp. 28-47). New York: Springer-Verlag.

Hogg, M. A., \& Abrams, D. (1993). Towards a single process uncertainty-reduction model of social motivation in groups. In M. A. Hogg \& D. Abrams (Eds.), Group motivation: Social psychological perspectives (pp. 173-190). New York: Harvester Wheatsheaf.

Hogg, M. A., \& Mullin, B.-A. (1999). Joining groups to reduce uncertainty: Subjective uncertainty reduction and group identification. In D. Abrams \& M. A. Hogg (Eds.), Social identity and social cognition (pp. 249-279). Oxford, UK: Blackwell.

Holmes, J. G., \& Rempel, J. K. (1989). Trust in close relationships. In C. Hendrick (Ed.), Close relationships: Review of personality and sacial psychology (Vol. 10, pp. 187-220). London: Sage.

Homans, G. C. (1961). Social behavior: Its elementary forms. New York: Harcourt, Brace, \& World.

Hunton, J. E. Hall, T. W., \& Price, K. H. (1998). The value of voice in participative decision making. Joumal of Applied Psychology, 83, 788-797.

Huo, Y. J., Smith, H. J., Tyler, T. R., \& Lind, E. A. (1996). Superordinate identification, subgroup identification, and justice concerns: Is separatism the problem: is assimilation the answer? Psychological Science, $7,40-45$.

Jost, J. T. (1995). Negative illusions: Conceptual clarification and psychological evidence concerning false consciousness. Political Psychology, 16, 397-424. 
Jost, J. T., \& Banaji, M. R. (1994). The role of stereotyping in system-justification and the production of false consciousness. British Journal of Social Psychology, 33, 1-27.

Kagan, J. (1972). Motives and development. Journal of Personality and Social Psychology, 22, 51-66.

Kahneman, D., Slovic, P., \& Tversky, A. (Eds.). (1982). Judgment under uncertainty: Heuristics and biases. New York: Cambridge Univ. Press.

Kelley, H. H., \& Thibaut, J. W. (1978). Interpersonal relations: A theory of interdependence. New York: Wiley.

Kidwell, R. E., \& Bennett, N. (1994). Employee reactions to electronic systems. Group and Organization Management, 19, 203-218.

Kim, W. C., \& Mauborgne, R. (1997). Fair process: Managing in the knowledge economy. Harvard Business Review, 75, 65-75.

King, G. A., \& Sorrentino, R. M. (1988). Uncertainty orientation and the relationship between individual accessible constructs and person memory. Social Cognition, 6, 128-149.

Kirkman, B. L., Shapiro, D. L., Novelli, L. Jr., \& Brett, J. (in press). Employee concerns regarding self-managing work teams: A multidimensional justice perspective. Social Justice Research.

Konovsky, M., \& Folger, R. (1991. August). The effects of procedural and distributive justice on organizational citizenship behavior. Paper presented at the annual meeting of the Academy of Management, Miami Beach, FL.

Koper, G., Van Knippenberg, D., Bouhuijs, F., Vermunt, R., \& Wilke, H. (1993). Procedural faimess and self-esteem. European Journal of Social Psychology, 23, 313-325.

Korsgaard, M. A., Schweiger, D. M., \& Sapienza, H. J. (1995). Building commitment, attachment, and trust in strategic decision-making teams: The role of procedural justice. Academy of Management Journal, $38,60-84$.

Kruglanski, A. W. (1989). Lay epistemics and human knowledge: Cognitive and motivational bases. New York: Plenum.

Kruglanski, A. W., \& Webster, D. M. (1996). Motivated closing of the mind: "Seizing" and "freezing." Psychological Review, 103, 263-283.

Kuhn, K. M., \& Sniezek, J. A. (1996). Confidence and uncertainty in judgmental forecasting: Differential effects of scenario presentation. Journal of Behavioral Decision Making, 9. 231-247.

Langer, E. J. (1975). The illusion of control. Journal of Personality and Social Psychology, 32, 311-328.

Leary, M. R. \& Baumeister, R. F. (2000). The nature and function of self-esteem: Sociometer theory. In M. P. Zanna (Ed.), Advances in experimental social psychology (Vol. 32, pp. 1-62). New York: Academic Press.

Lerner, M. J. (1977). The justice motive: Some hypotheses as to its origins and forms. Joumal of Personality, 45, 1-52.

Lerner, M. J. (1980). The belief in a just world: A fundamental delusion. New York: Plenum.

Lerner, M. J., \& Miller, D. T. (1978). Just world research and the attribution process: Looking back and ahead, Psychological Bulletin, 85, 1030-1051.

Lemer, M. J., \& Whitehead, L. A. (1980). Procedural justice viewed in the context of justice motive theory. In G. Mikula (Ed.), Justice and social interaction: Experimental and theoretical contributions from psychological research (pp. 219-256). Bern, Austria: Huber.

Leventhal, G. S. (1980). What should be done with equity theory? New approaches to the study of fairness in social relationships. In K. J. Gergen, M. S. Greenberg, \& R. H. Willis (Eds.), Social exchange: Advances in theory and research (pp. 27-54). New York: Plenum.

Lind, E. A. (1990). Arbitrating high-stakes cases: An evaluation of court-annexed arbitration in a United States district court. Santa Monica, CA: Rand Corporation.

Lind, E. A. (1992, March). The fairness heuristic: Rationality and "relationality" in procedural evaluations. Paper presented at the Fourth International Conference of the Society for the Advancement of Socio-Economics, Irvine, CA.

Lind, E. A. (1994). Experimental studies of procedural justice. Unpublished manuscript. 
Lind, E. A. (1995). Justice and authority relations in organizations. In R. Cropanzano \& K. M. Kacmar (Eds.), Organizational politics, justice, and support: Managing the social climate of the workplace (pp. 83-96). Westport, CT: Quorom.

Lind, E. A. (2001). Faimess heuristic theory: Justice judgments as pivotal cognitions in organizational relations. In J. Greenberg \& R. Cropanzano (Eds.), Advances in organizational behavior (pp. 56-88). Stanford, CA: Stanford Univ. Press.

Lind, E. A., Greenberg, J., Scott, K. S., \& Welchans, T. D. (2000). The winding road from employee to complainant: Situational and psychological determinants of wrongful termination claims. Administrative Science Quarterly, 45, 557-590.

Lind, E. A., Kanfer, R., \& Earley, P. C. (1990). Voice, control, and procedural justice: Instrumental and noninstrumental concerns in faimess judgments. Joumal of Personality and Social Psychology, 59, 952-959.

Lind, E. A., Kray, L., \& Thompson, L. (2001). Primacy effects in justice judgments: Testing predictions from fairness heuristic theory. Organizational Behavior and Human Decision Processes, 85, 189 210.

Lind, E. A., Kulik, C. T., Ambrose, M., \& De Vera Park, M. V. (1993). Individual and corporate dispute resolution: Using procedural fairness as a decision heuristic. Administrative Science Quarterly, $38,224-251$.

Lind, E. A., \& Tyler, T. R. (1988). The social psychology of procedural justice. New York: Plenum.

Lind, E. A., Tyler, T. R., \& Huo, Y. J. (1997). Procedural context and culture: Variation in the antecedents of procedural justice judgments. Joumal of Personality and Social Psychology, 73, 767780.

Loewenstein, G. F. (1996). Out of control: Visceral influences on behavior. Organizational Behavior and Human Decision Processes, 65, 272-292.

Lopes, L. L. (1987). Between hope and fear: The psychology of risk. Advances in Experimental Psychology, 20, 255-295.

Lord, A., \& Hartley, J. (1998). Organizational commitment and job insecurity in a changing public service organization. European Journal of Work and Organizational Psychology, 7, 341-354.

MacCrimmon, K. R., \& Wehrung, D. A. (1986). The management of uncertainty. New York: Free Press.

Major, B. (1994). From social inequality to personal entitlement: The role of social comparisons, legitimacy appraisals, and group membership. In M. P. Zanna (Ed.). Advances in experimental social psychology (Vol. 26, pp. 293-355). San Diego, Academic Press.

Markovsky, B. (1988). Anchoring justice. Social Psychology Quarterly, 51, 213-224.

Martin, L. L. (1999). I-D compensation theory: Some implications of trying to satisfy immediate-return needs in a delayed-retum culture. Psychological lnquiry, 10, 195-208.

McFarlin, D. B., \& Sweeney, P. D. (1992), Distributive and procedural justice as predictors of satisfaction with personal and organizational outcomes. Academy of Management Joumal, 35, 626-637.

McGregor, I. Zanna, M. P. Holmes, J. G., \& Spencer, S. J. (2001). Compensatory conviction in the face of personal uncertainty: Going to extremes and being oneself. Joumal of Personality and Social Psychology, 80, 472-488.

Messick, D. M. (1993). Equality as a decision heuristic. In B. A. Mellers \& J. Baron (Eds.), Psycholog. ical perspectives on justice: Theory and applications (pp. 11-31). Cambridge, MA: Cambridge Univ. Press.

Messick, D. M., \& Schell, T. (1992). Evidence for an equality heuristic in social decision making. Acta Psychologica, 80, 311-323.

Messick, D. M., \& Sentis, K. (1983). Fairness, preference, and fairness biases. In D. M. Messick \& K. S. Cook (Eds.), Equity theory: Psychological and sociological perspectives (pp. 61-94). New York: Praeger.

Miedema, J., Van den Bos, K., \& Vermunt, R. (2000). Unpublished raw data. 
Mikula, G. (1984). Justice and faimess in interpersonal relations: Thoughts and suggestions. In H. Tajfel (Ed.), The social dimension: European developments in social psychology (pp. 204-227). Cambridge, MA: Cambridge Univ. Press.

Mikula, G., \& Wenzel, M. (2000). Justice and social conflict. International Joumal of Psychology, 35, 126-135.

Moorman, R. H. (1991). Relationship between organizational justice and organizational citizenship behaviors: Do fairness perceptions influence employee citizenship? Joumal of Applied Psychology, 76. 845-855.

Nickels, J. B., Cramer, K. M., \& Gural, D. M. (1992). Toward unconfounding prediction and control: Predictionless control made possible. Canadian Journal of Behavioural Science, 24, 156-170.

Nisbett, R. E., \& Ross, L. (1980). Human inference: Strategies and shortcomings of social judgment. Englewood Cliffs, NJ: Prentice Hall.

Paternoster, R., Brame, R., Bachman, R., \& Sherman, L. W. (1997), Do fair procedures matter? The effect of procedural justice on spouse assault. Law and Society Review, 31, 163-204.

Parker, C. P., Bales, B. B., \& Christensen, N. D. (1997). Support for affirmative action, justice perceptions, and work attitudes: A study of gender and racial-ethnic group differences. Journal of Applied Psychology, 82, 376-389.

Podsakoff, P. M., \& MacKenzie, S. B. (1993). Citizenship behavior and fairness in organizations: Issues and directions for future research. Employee Responsibilities and Rights Joumal, 6, 235-247.

Pratto, F., Sidanius, J., Stallworth, L. M., \& Malle, B. F. (1994). Social dominance orientation: A personality variable predicting social and political attitudes. Journal of Personality and Social Psychology, 67, 741-763.

Pyszczynski, T. A., Greenberg, J., \& Solomon, S. (1999). A dual-process model of defense against conscious and unconscious death-related thoughts: An extension of terror management theory. Psychological Review, 106, 835-845.

Reis, H. T. (1984). The multidimensionality of justice. In R. Folger (Ed.), The sense of injustice: Social psychological perspectives (pp. 25-61). New York: Plenum.

Ric, F. (1997). Effects of control deprivation on subsequent use of stereotypes. The Journal of Social Psychology, 137, 333-342.

Rokeach, M. (1948). Generalized mental rigidity as a factor in ethnocentrism. Joumal of Abnormal Social Psychology, 43, 259-278.

Rokeach, M. (1960). The open and closed mind. New York: Basic Books.

Roney, J. R., \& Sorrentino, R. M. (1995). Self-evaluation motives and uncertainty orientation: Asking the "who" question. Personality and Social Psychology Bulletin, 21, 1319-1329.

Rosenberg, M. (1979). Conceiving the self. New York: Basic Books.

Rosenblatt, A., Greenberg, J., Solomon, S., Pyszczynski, T., \& Lyon, D. (1989), Evidence for terror management theory. I. The effects of mortality salience on reactions to those who violate or uphold cultural values, Joumal of Personalisy and Social Psychology. 57, 681-690.

Rutte, C. G., \& Messick, D. M. (1995). An integrated model of perceived unfaimess in organizations. Social Justice Research, 8, 239-261.

Schwarz, N., \& Clore, G. L. (1983). Mood, misattribution, and judgments of well-being: Informative and directive functions of affective states. Journal of Personality and Social Psychology, 45, 513523.

Sedikides, C., \& Strube, M. J. (1995). The multiply motivated self. Personality and Social Psychology Bulletin, 21, 1330-1335.

Sedikides, C., \& Strube, M. J. (1997). Self-evaluation: To thine own self be good, to thine own self be sure, to thine own self be true, and to thine own self be better. In M. P. Zanna (Ed.), Advances in experimental social psychology (Vol. 29, pp. 209-269)., San Diego, CA: Academic Press.

See, K. E. (2000). Interactional effects of faimess and knowledge in outcome acceptance decisions. Unpublished manuscript. 
Shapira, Z. (1995). Risk taking: A managerial perspective. New York: Sage.

Skitka, L. J. (in press). Do the means always justify the ends, or do the ends sometimes justify the means? A value protection model of justice. Personality and Social Psychology Bulletin.

Smith, H. J., \& Tyler, T. R. (1997). Choosing the right pond: The impact of group membership on selfesteem and group-oriented behavior. Joumal of Experimental Social Psychology, 33, 146-170.

Smith, H. J., Tyler, T. R., Huo, Y. J., Ortiz, D. J., \& Lind, E. A. (1998). The self-relevant implications of the group-value model: Group-membership, self-worth and treatment quality. Journal of Experimental Social Psychology, 34, 470-493.

Sniezek, J. A., May, D. R., \& Sawyer, J. E. (1990). Social uncertainty and interdependence: A study of resource allocating decisions in groups. Organizational Behavior and Human Decision Processes. 46, $155-180$.

Solomon, S., Greenberg, J., \& Pyszczynski, T. (1991). A terror management theory of social behavior: The psychological functions of self-esteem and cultural worldviews. In M. P. Zanna (Ed.), Advances in experimental social psychology (Vol. 24, pp. 93-159). New York: Academic Press.

Sorrentino, R. M., Bobocel, D. R., Gitta, M. Z., Olson, J. M., \& Hewitt, E. C. (1988). Uncertainty orientation and persuasion: Individual differences in the effects of personal relevance on social judgments. Joumal of Personality and Social Psychology, 55, 357-337.

Sorrentino, R. M., Hodson, G. L. \& Huber, G. L. (in press). Uncertainty orientation and the interpersonal context. In J. P. Forgas, K. D. Williams, \& L. Wheeler (Eds.), The social mind: Cognitive and motivational aspects of interpersonal behavior. New York: Cambridge Univ. Press.

Sorrentino, R. M., Holmes, J. G., Hanna, S. E., \& Sharp, A. (1995). Uncertainty orientation and trust in close relationships: Individual differences in cognitive styles. Journal of Personality and Social Psychology, 68, 314-327.

Sorrentino, R. M., \& Roney, C. J. R. (1986). Uncertainty orientation, achievement-related motivation and task diagnosticity as determinants of task performance. Social Cognition, 4, 420-436.

Sorrentino, R. M., \& Short, J. C. (1986). Uncertainty orientation, motivation and cognition. In R. M. Sorrentino \& E. T. Higgins (Eds.). The handbook of motivation and cognition: Foundations of social behavior (Vol. 1, pp. 379-403). New York: Guilford.

Sorrentino, R. M., Short, J.-A. C., \& Raynor, J. O. (1984). Uncertainty orientation: Implications for affective and cognitive views of achievement behavior. Journal of Personality and Social Psychology, 46, 189-201.

Spreitzer, G. M., \& Mishra, A. K. (1999). Giving up control without losing control: Trust and its sub. stitutes' effects on managers: Involving employees in decision making. Group and Organization Management, 24, 155-187.

Stapel, D. A., \& Koomen, W. (2001). The impact of interpretation versus comparison goals on knowledge accessibility effects. Joumal of Experimental Sacial Psychology, 37, 134-139.

Steiner, D. D., Guirard, S., \& Baccino, T. (1999, May). Cognitive processing of procedural justice information: Application of the oculometer. Paper presented at the Annual Conference of the Society for Industrial/Organizational Psychology, Atlanta, GA.

Stouffer, S. A., Suchman, E. A., DeVinney, L. C., Star, S. A., \& Williams, R. M. (1949), The American soldier: Adjustment during Army life (Vol. 1). Princeton, NJ: Princeton Univ. Press.

Swann, W. B., Jr., \& Schroeder, D. G. (1995). The search for beauty and truth: A framework for understanding reactions to evaluations. Personality and Social Psychology Bulletin, 21, 13071318.

Tan, H.-T., \& Lipe, M. G. (1997). Outcome effects: The impact of decision process and outcome controllability. Joumal of Behavioral Decision Making, 10, 315-325.

Tanaka, K., \& Takimoto, S. (1997). Effects of interpersonal affect upon fairness judgment. Japanese Psychological Research, 39, 312-322.

Taylor, D. M., Wright, S. C., \& Porter, L. (1994). Dimensions of perceived discrimination: The personal/group discrimination discrepancy, In M. P. Zanna \& J. M. Olson (Eds.), The psychology of prejudice. Hillsdale, NJ: Erlbaum. 
Tesser, A. (2000). On the confluence of self-esteem maintenance mechanisms. Personality and Social Psychology Review, 4, 290-299.

Thibaut, J., \& Walker, L. (1975). Procedural justice: A psychological analysis. Hillsdale, NJ: Erlbaum.

Thompson, M. M., \& Zanna, M. P. (1995). The conflicted individual: Personality-based and domainspecific antecedents of ambivalent social attitudes. Journal of Personality, 63, 259-288.

Thompson, S. C., Armstrong, W., \& Thomas, C. (1998). Illusions of control, underestimations, and accuracy: A control heuristic explanation. Psychological Bulletin, 123, 143-161.

Treadwell, J. R., \& Nelson, T. O. (1997). Availability of information and the aggregation of confidence in prior decisions. Organizational Behavior and Human Decision Processes, 68, 13-27.

Tversky, A., \& Kahneman, D. (1974). Judgment under uncertainty: Heuristics and biases. Science, $185,1124-1134$.

Tyler, T. R. (1990). Why do people obey the law? Procedural justice, legitimacy, and compliance. New Haven, CT: Yale Univ. Press.

Tyler. T. R. (1997). The psychology of legitimacy: A relational perspective on voluntary deference to authorities. Personaliry and Social Psychology Review, 1, 323-345.

Tyler, T. R., Boeckmann, R. J., Smith, H. J., \& Huo, Y. J. (1997). Social justice in a diverse society. Boulder, CO: Westview.

Tyler, T. R., \& Caine, A. (1981). The influence of outcomes and procedures on satisfaction with formal leaders. Journal of Personality and Social Psychology, 41, 642-655.

Tyler, T. R., \& DeGocy, P. (1996). Trust in organizational authorities: The influence of motive attributions on willingness to accept decisions. In R. Kramer \& T. R. Tyler (Eds.), Trast in organizations: Frontiers of theory and research (pp. 331-356). Thousand Oaks, CA: Sage.

Tyler, T. R., DeGoey, P., \& Smith, H. J. (1996). Understanding why the justice of group procedures matters: A test of the psychological dynamics of the group-value model. Journal of Personality and Social Psychology, 70, 913-930.

Tyler, T. R., \& Folger, R. (1980). Distributional and procedural aspects of satisfaction with citizenpolice encounters. Basic and Applied Social Psychology, 1, 281-292.

Tyler, T. R., \& Lind, E. A. (1992). A relational model of authority in groups. In M. P. Zanna (Ed.), Advances in experimental social psychology (Vol. 25, pp. 115-191). San Diego, CA: Academic Press.

Tyler, T. R., Rasinski, K. A., \& McGraw, K. M. (1985). The influence of perceived injustice on the endorsement of political leaders. Journal of Applied Social Psychology, 15, 700-725.

Tyler, T. R., Rasinski, K. A., \& Spodick, N. (1985). Influence of voice on satisfaction with leaders: Exploring the meaning of process control. Joumal of Personality and Social Psychology, 48, 72-81.

Tyler, T. R., \& Smith, H. J. (1998). Social justice and social movements. In D. Gilbert, S. T. Fiske, \& G. Lindzey (Eds.), Handbook of social psychology (4th ed., Vol. 2, pp. 595-629). Boston, MA: McGraw-Hill.

Van den Bos, K. (1999). What are we talking about when we talk about no-voice procedures? On the psychology of the fair outcome effect. Joumal of Experimental Social Psychology, 35, 560-577.

Van den Bos, K. (2001a). Uncertainty management: The influence of uncertainty salience on reactions to perceived procedural fairness. Journal of Personality and Social Psychology, 80, 931-941.

Van den Bos, K. (2001b). Fairness heuristic theory: Assessing the information to which people are reacting has a pivotal role in understanding organizational justice. In S. W. Gilliland, D. D. Steiner, \& D. P. Skarlicki (Eds.), Theoretical and cultural perspectives on organizational justice ( $\mathrm{pp}, 63$ 84). Greenwich, CT: Information Age.

Van den Bos, K. (2001c). Reactions to perceived faimess: The impact of mortality salience and selfesteem on ratings of negative affect. Social Justice Research, 14, 1-23.

Van den Bos, K. (in press). Assimilation and contrast in organizational psychology: The role of primed mindsets in the psychology of the fair process effect. Organizational Behavior and Human Decision Processes. 
Van den Bos, K., Bruins, J., Wilke, H. A. M., \& Dronkert, E. (1999). Sometimes unfair procedures have nice aspects: On the psychology of the fair process effect. Journal of Personality and Social Psychology, 77, 324-336.

Van den Bos, K., \& Lind, E. A. (2001). The psychology of own versus others' treatment: Self-oriented and other-oriented effects on perceptions of procedural justice. Personality and Social Psychology Bulletin, 27, 1324-1333.

Van den Bos, K., Lind, E. A., Vermunt, R., \& Wilke, H. A. M. (1997). How do I judge my outcome when I do not know the outcome of others? The psychology of the fair process effect. Journal of Personality and Social Psychology, 72, 1034-1046.

Van den Bos, K., Lind, E. A., \& Wilke, H. A. M. (2001). The psychology of procedural and distributive justice viewed from the perspective of faimess heuristic theory. In R. Cropanzano (Ed.), Justice in the workplace: Volume 2. From theory to practice (pp. 49-66). Mahwah, NJ: Erlbaum.

Van den Bos, K., \& Miedema, J. (2000). Toward understanding why faimess matters: The influence of mortality salience on reactions to procedural fairness. Journal of Personality and Social Psychology, 79, 355-366.

Van den Bos, K., \& Van Prooijen, J.-W. (2001). Referent cognitions theory: The role of closeness of reference points in the psychology of voice. Joumal of Personality and Social Psychology, 81, 616-626.

Van den Bos, K., Van Schie, E. C. M., \& Colenberg, S. E. (in press). Parents' reactions to child day care organizations: The influence of perceptions of procedures and the role of organizations' trustworthiness. Social Justice Research.

Van den Bos, K., Vermunt, R., \& Wilke, H, A. M. (1996). The consistency rule and the voice effect: The influence of expectations on procedural faimess judgements and performance. European Joumal of Social Psychology, 26, 411-428.

Van den Bos, K., Vermunt, R., \& Wilke, H. A. M. (1997). Procedural and distributive justice: What is fair depends more on what comes first than on what comes next. Joumal of Personality and Social Psychology, 72, 95-104.

Van den Bos, K., Wilke, H. A. M., \& Lind, E. A. (1998). When do we need procedural faimess?: The role of trust in authority. Journal of Personality and Social Psychology, 75, 1449-1458.

Van den Bos, K., Wilke, H. A. M., Lind, E. A., \& Vermunt, R. (1998). Evaluating outcomes by means of the fair process effect: Evidence for different processes in fairness and satisfaction judgments. Journal of Personality and Social Psychology, 74, 1493-1503.

Van Dijk, E., Wilke, H. A. M., Wilke, M., \& Metman, L. (1997). What information do we use in social dilemmas?: Environmental uncertainty and the employment of coordination rules. Journal of Experimental Social Psychology, 35, 109-135.

Vermunt, R., Van Knippenberg, D., Van Knippenberg, B., \& Blaauw, E. (2001). Self-esteem and outcome faimess: Differential importance of procedural and outcome considerations. Joumal of Applied Psychology, 86, 621-628.

Vermunt, R.. Wit, A., Van den Bos, K., \& Lind, A. (1996), The effect of inaccurate procedure on protest: The mediating role of perceived unfairness and situational self-esteem. Social Justice Research, 9. 109-119.

Walster, E., Berscheid, E., \& Walster, G. W. (1973). New directions in equity research. Journal of Personality and Social Psychology, 25, 151-176.

Walster, E., Walster, G. W., \& Berscheid, E. (1978). Equity: Theory and research. Boston: Allyn \& Bacon.

Winder, A. B., Kerkhof, P.. \& Klandermans, P. G. (1999), Werknemers over de OR: Vragen over effectiviteit, communicatie en rechtvaardigheid [Employees about work councils: Questions about effectiveness, communication, and justice]. The Hague, The Netherlands: A+O Fonds Gemeenten.

Wright, R. (1994). The moral animal: Why we are the way we are-The new science of evolutionary psychology. New York: Pantheon. 